\title{
Elephants respond to resource trade-offs in an aseasonal system through daily and annual variability in resource selection
}

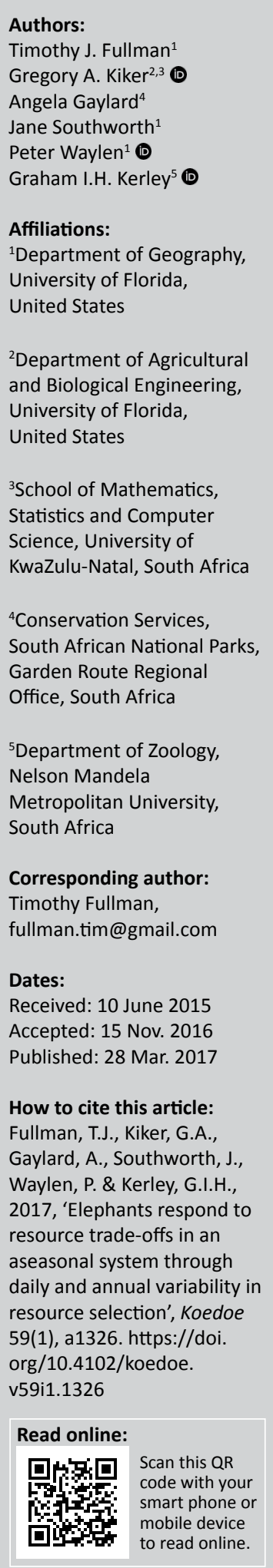

Animals and humans regularly make trade-offs between competing objectives. In Addo Elephant National Park (AENP), elephants (Loxodonta africana) trade off selection of resources, while managers balance tourist desires with conservation of elephants and rare plants. Elephant resource selection has been examined in seasonal savannas, but is understudied in aseasonal systems like AENP. Understanding elephant selection may suggest ways to minimise management trade-offs. We evaluated how elephants select vegetation productivity, distance to water, slope and terrain ruggedness across time in AENP and used this information to suggest management strategies that balance the needs of tourists and biodiversity. Resource selection functions with time-interacted covariates were developed for female elephants, using three data sets of daily movement to capture circadian and annual patterns of resource use. Results were predicted in areas of AENP currently unavailable to elephants to explore potential effects of future elephant access. Elephants displayed dynamic resource selection at daily and annual scales to meet competing requirements for resources. In summer, selection patterns generally conformed to those seen in savannas, but these relationships became weaker or reversed in winter. At daily scales, resource selection in the morning differed from that of midday and afternoon, likely reflecting trade-offs between acquiring sufficient forage and water. Dynamic selection strategies exist even in an aseasonal system, with both daily and annual patterns. This reinforces the importance of considering changing resource availability and trade-offs in studies of animal selection.

Conservation implications: Guiding tourism based on knowledge of elephant habitat selection may improve viewing success without requiring increased elephant numbers. If AENP managers expand elephant habitat to reduce density, our model predicts where elephant use may concentrate and where botanical reserves may be needed to protect rare plants from elephant impacts.

\section{Introduction}

Conservation often involves trade-offs between competing goals and objectives. While trade-offs between biodiversity conservation and human needs have been emphasised (e.g. Hirsch et al. 2011; McShane et al. 2011), it is also important to take into account trade-offs between conserving different aspects of biodiversity. In Addo Elephant National Park (AENP), South Africa, managers seek to balance the local conservation of African elephants (Loxodonta africana) and the ecological processes they provide with protecting rare plants and providing for tourism.

The park was founded in 1931 to protect the remnant population of elephants in the Eastern Cape Province following depletion by hunting (Hall-Martin 1980). Fences were erected in 1954 to prevent conflict with farmers, and the population rapidly grew to its current level of over 500 elephants (Hall-Martin 1980; SANParks 2011). Although elephants comprise around $80 \%$ of the herbivore biomass in AENP (Landman et al. 2012), the park is also home to 19 other large mammal species (SANParks 2008). This diversity of species attracts national and international tourists, with over $90 \%$ of tourists rating wildlife viewing as a 'very important' motivation for visiting (Boshoff et al. 2007). Demand by tourists for wildlife viewing opportunities sometimes leads to stocking high densities of tourist-favoured species, such as elephants. Such actions, however, may fail to meet tourism objectives and may conflict with the South African National Parks (SANParks) mandate to preserve diverse, healthy ecosystems (Maciejewski \& Kerley 2014). This mismatch is especially crucial in AENP, which contains a wide variety of rare and important plant species in addition to animals (Lombard et al. 2001). The park contains portions of five of the nine

Copyright: (C 2017. The Authors. Licensee: AOSIS. This work is licensed under the Creative Commons Attribution License. 
South African biomes, comprising 43 different vegetation units (SANParks 2008). Concerns about disturbance of vegetation by elephants have been raised by several studies that documented loss of plant biodiversity and biomass (Kerley \& Landman 2006; Landman, Kerley \& Schoeman 2008; Lombard et al. 2001). A better understanding of the factors influencing elephant movement is needed to inform conservation decisions by park managers regarding wildlife, rare plants and tourism (Ferreira et al. 2011). Such information can be used to identify where high elephant use coincides with rare plant hotspots, suggesting locations for enclosure with fences to protect rare plants from elephants and other herbivores. It can also help guide tourist viewing to maintain a balance between ecological health and visitor satisfaction. Currently elephants are fenced into three discrete sections of AENP, occupying about 60000 ha of the total 160000 ha area of the park (Ferreira et al. 2011). Understanding how elephants use resources in the currently accessible areas of AENP will clarify possible effects of future expansion of access to other areas of the park.

We investigate elephant resource selection through satellite imagery and movement data to evaluate how elephant space use responds to vegetation productivity (greenness), artificial water points, slope and terrain ruggedness across space and time in AENP. While numerous studies consider the influence of vegetation, water and other factors on elephant movement and distribution (e.g. Chamaillé-Jammes et al. 2013; Loarie, Van Aarde \& Pimm 2009b; Marshal et al. 2011; Roever, Van Aarde \& Leggett 2012), they are generally conducted in savanna systems, featuring distinct wet and dry seasons, with differing factors influencing elephant habitat selection in each season (Loarie et al. 2009b; Roever et al. 2012). AENP, on the contrary, exhibits no strong seasonal rainfall pattern (Ferreira et al. 2011; Gough \& Kerley 2006) and features evergreen succulent thicket in the main elephant areas (Landman et al. 2008), rather than the savanna vegetation of trees and grasses typical of elephant populations elsewhere. It is unclear how elephant resource use in aseasonal thicket will differ from resource use in savanna systems.

As a set of non-exclusive hypotheses, we predict that elephant resource selection in the aseasonal thicket of AENP will correspond to that observed in savanna environments. While selection patterns may well differ in an aseasonal thicket ecosystem, these hypotheses provide a basis for comparison. Elephants must consume great quantities of forage to sustain their large body size and high absolute metabolic requirements (Hopcraft, Olff \& Sinclair 2010). Positive selection for green vegetation has been indicated in several studies of elephant habitat use (Loarie et al. 2009b; Pittiglio et al. 2012; Wall et al. 2013; but see Boettiger et al. 2011). Elephants are waterdependent herbivores and typically require access to drinking water every day or two (Chamaillé-Jammes et al. 2013; OwenSmith et al. 2006). Water availability alters elephant movement and distribution patterns (Chamaillé-Jammes, Valeix \& Fritz 2007; Loarie, Van Aarde \& Pimm 2009a; Shannon et al. 2009; Smit, Grant \& Whyte 2007a), with elephants typically selecting for areas near water. Steep slopes require high energy expenditures from elephants because of their large body size, and thus tend to be avoided (Roever et al. 2012; Wall, DouglasHamilton \& Vollrath 2006). Rugged terrain is preferentially used by elephants because of the presence of greater nutrient concentrations and forage density compared with less rugged areas (Nellemann, Moe \& Rutina 2002). In summary, if elephants in aseasonal AENP follow the patterns exhibited by elephants in seasonal systems, we expect them to show (1) a positive association with vegetation greenness, (2) a negative association with distance to water, (3) a negative association with steeper slopes and (4) a positive association with more rugged terrain.

We use step selection functions (Forester, Im \& Rathouz 2009; Fortin et al. 2005) to evaluate the hypotheses identified above, measuring elephant resource selection at a daily scale in AENP. Environmental covariates are interacted with functions of time to investigate annual variability in selection patterns, while three data sets of daily movement steps recorded in the morning (06:00), midday (12:00) and afternoon (16:00) are analysed to reflect circadian patterns of resource selection. We use the results of these analyses to suggest implications for management that balance the needs of elephants, the demands of tourists and the potential of future elephant expansion to other areas of AENP.

\section{Research method and design}

\section{Study area}

AENP lies along the southern coast of South Africa (Figure 1) and features an aseasonal climate (Figure 1-A1), with about $400 \mathrm{~mm}-450 \mathrm{~mm}$ of year-round rainfall (Gough \& Kerley 2006; Lombard et al. 2001). There are no permanent natural

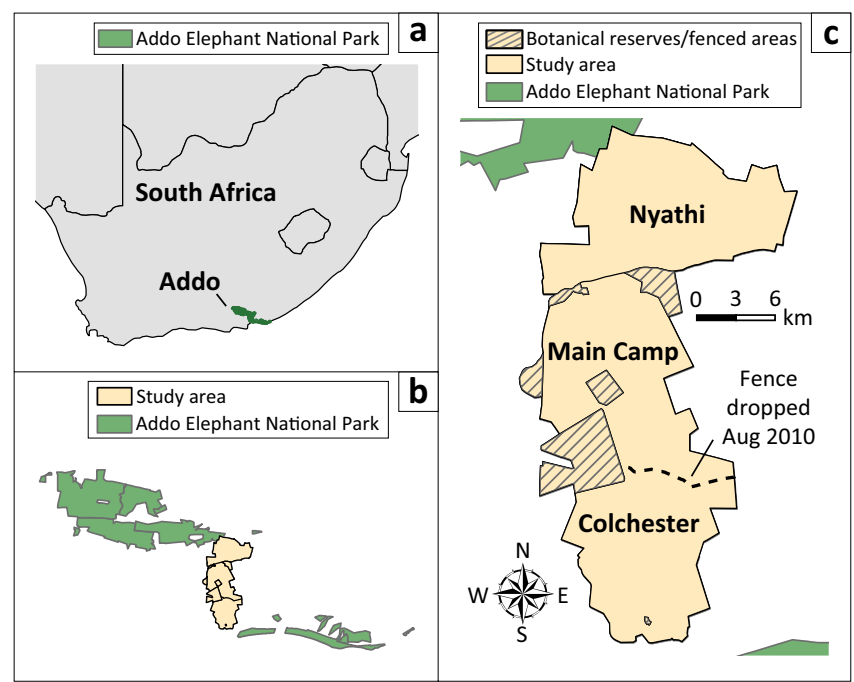

FIGURE 1: (a) Addo Elephant National Park exists in an aseasonal climatic system on the South African coast. (b) The elephant-accessible areas evaluated in this study lie at the heart of the larger Addo Elephant National Park. (c) Primary elephant-accessible areas of Addo Elephant National Park. The fence separating Main Camp and Colchester was dropped in August 2010, making both sections available to elephants. The Nyathi section remained isolated by fences from Main Camp for the duration of the study. Botanical reserves and other fenced areas are inaccessible to elephants. A smaller population of elephants occupies the Kuzuko section of Addo Elephant National Park (not pictured) and is not included in this study. 
water sources in the Main Camp and Colchester sections of the park (SANParks 2008), aside from a single brackish spring in Colchester. Instead, water is provided through artificial water points fed by pumped groundwater (Landman et al. 2012).

For most of AENP's history, elephants were confined primarily within the Main Camp section of the park (Figure 1c). As the elephant population grew, this section was enlarged, increasing from $22.7 \mathrm{~km}^{2}$ at the time of fencing to 120.0 km$^{2}$ in 2008 (Gough \& Kerley 2006; Hall-Martin 1980; Landman et al. 2012). Several areas within the elephantaccessible portion of the park were fenced off as botanical reserves to protect vulnerable plants from elephants and other herbivores (Figure 1c; Lombard et al. 2001). In August 2010, the fence separating the Main Camp and Colchester sections of AENP (Figure 1c) was removed, providing elephants with access to both areas. At the time of this study, most of the elephants in the park occupied the Main Camp/ Colchester section, with a smaller population separated by a fence in the Nyathi section (Figure 1c; SANParks 2011). A third, even smaller population was established in the Kuzuko section of AENP in 2005.

Other sections not available to elephants have also been added to AENP over time to expand protection of the diverse biomes in the region (Figure 1b). In the late 1990s, a 'Greater Addo Elephant National Park' was proposed to offer a combination of terrestrial and marine areas that would promote both conservation and development (Kerley \& Boshoff 1997). While elephants currently do not have access to these areas, there is interest by park management in expanding elephant access to other sections.

\section{Data description}

\section{Elephant telemetry data}

Geographic positioning system (GPS) collar data (Africa Wildlife Tracking, Pretoria, South Africa) were obtained for seven female elephants, each representing a different family group. Elephants were collared by SANParks veterinarians following established animal care protocols. Six of the collared elephants occupied the Main Camp - Colchester section of AENP, while one occupied the Nyathi section (Figure 1c). Collars recorded location data at frequencies ranging from hourly to three records per day between March 2010 and March 2013. Records were filtered to create three data sets of daily observations: daily locations at 06:00, 12:00 and 16:00. Positional dilution of precision (PDOP) records for each collar indicated high levels of accuracy (Table 1-A2; D’Eon \& Delparte 2005).

\section{Remotely sensed vegetation data}

Vegetation data were obtained from the Moderate Resolution Imaging Spectroradiometer (MODIS). The MOD13Q1 product provided vegetation indices at a $250 \mathrm{~m}$ spatial resolution in 16-day composites. Each pixel in a composite contained the maximum observation across the 16-day period to reduce issues associated with clouds, aerosol loading and shadows (Huete et al. 2011). Normalised Difference Vegetation Index (NDVI) layers from MODIS tile H20V12 were obtained from the USGS Land Processes Distributed Active Archive Center (https://www.lpdaac.usgs.gov/) for the period spanning from 06 March 2010 to 21 March 2013. NDVI indicates the 'greenness' of plants across the landscape (Huete, Justice \& Van Leeuwen 1999), reflecting vegetation productivity (Pettorelli et al. 2005) and nutritional quality (Loarie et al. 2009b). It is commonly used in wildlife ecology and management (Pettorelli et al. 2011) and in studies of elephant movement (e.g. Boettiger et al. 2011; Marshal et al. 2011). Preprocessing of MODIS composites was conducted using the MODIS Reprojection Tool (https://www.lpdaac.usgs.gov/ tools/modis_reprojection_tool) and ArcGIS (Version 9.3, ESRI, Redlands, CA). This included projecting MODIS composites to Universal Transverse Mercator (UTM) zone 35S and resampling using nearest neighbour sampling to ensure pixels were exactly $250 \mathrm{~m} \times 250 \mathrm{~m}$. All data with pixel qualities of 0 and 1 were retained for analysis, based on the pixel reliability summary provided with the MOD13Q1 data.

\section{Other covariate data}

In addition to NDVI, covariate data were obtained for the distance to artificial water points (hereafter distance to water), slope and terrain ruggedness (Figure 2-A1). Distance to water was calculated in ArcGIS at a $250 \mathrm{~m}$ spatial resolution using shapefiles of water point locations obtained from SANParks. Elevation data were obtained at a $30 \mathrm{~m} \times 30 \mathrm{~m}$ resolution from the ASTER Global Digital Elevation Model V2 (ASTER GDEM is a product of METI and NASA). Data were downloaded from NASA Reverb (http://www.reverb.echo.nasa.gov/) and then projected to UTM zone $35 \mathrm{~S}$ in ArcGIS. Block means were calculated on the elevation data using a $250 \mathrm{~m} \times 250 \mathrm{~m}$ rectangular neighbourhood to match the resolution of the NDVI and distance to water data. The resulting raster was resampled to a $250 \mathrm{~m}$ resolution using nearest neighbour sampling. Slope was calculated from the elevation raster using the Spatial Analyst toolbox in ArcGIS. Terrain ruggedness was calculated using the vector ruggedness measure (VRM) developed by Sappington, Longshore and Thompson (2007). This measure takes into account heterogeneity in both slope and aspect and yet has a low correlation with slope, allowing both measures to be included in analyses to represent different components of selection by animals (Sappington et al. 2007). Terrain ruggedness was calculated in ArcGIS using the VRM tool (VRM 2012) with a $3 \times 3$ pixel window on the $250 \mathrm{~m}$ elevation raster.

\section{Resource selection analysis}

Step selection functions (SSFs; Forester et al. 2009; Fortin et al. 2005) were developed using conditional logistic regression (CLR) models to investigate resource selection by elephants at a daily scale. These models, alternatively called discrete choice models, evaluate 'choice sets' contrasting characteristics of the choice made at a given time (the elephant location) with those that were available (other nearby locations; Duchesne, Fortin \& Courbin 2010; Manly et al. 2002). How 'available' locations are defined in such studies can strongly influence findings (Beyer et al. 2010). When used to evaluate 
resource selection functions, CLR models typically involve a matched design in which animal presence points are associated with 'available' locations drawn within a limited area (Boyce 2006; Duchesne et al. 2010). We sampled the empirical distribution of daily step lengths and turning angles for all individuals to determine our available locations (Forester et al. 2009). Step lengths and turning angles were calculated using the 'adehabitatLT' package in R (Calenge 2006; R Core Team 2016). Twenty available points were drawn for each observed elephant location, based on a sensitivity analysis (Appendix 3). Available points drawn from areas inaccessible to elephants (i.e. outside the park or within botanical reserves) were discarded and replacement points were drawn.

We developed a set of candidate models representing potential resource selection by elephants at a daily scale (Table 1) for locations recorded in the morning (06:00), midday (12:00) and afternoon (16:00). All models contained a spline for distance to the previous used point to help reduce bias in SSF estimation (Forester et al. 2009). Distance splines were included using the pspline function of the 'survival' package in R (Therneau 2015; Therneau \& Grambsch 2000) with two degrees of freedom, following the approach of Panzacchi et al. (2016). Variance inflation factors (VIF) were

TABLE 1: Candidate models for elephant resource selection in Addo Elephant National Park, South Africa.

\begin{tabular}{|c|c|}
\hline Model number & Model \\
\hline 1 & NDVI \\
\hline 2 & Slope \\
\hline 3 & Rugged \\
\hline 4 & DistW \\
\hline 5 & NDVI + Slope \\
\hline 6 & NDVI + Rugged \\
\hline 7 & NDVI + DistW \\
\hline 8 & Slope + Rugged \\
\hline 9 & Slope + DistW \\
\hline 10 & Rugged + DistW \\
\hline 11 & NDVI + Slope + Rugged \\
\hline 12 & NDVI + Slope + DistW \\
\hline 13 & NDVI + Rugged + DistW \\
\hline 14 & Slope + Rugged + DistW \\
\hline 15 & NDVI + Slope + Rugged + DistW \\
\hline 16 & NDVI $\times$ Time \\
\hline 17 & Slope $\times$ Time \\
\hline 18 & Rugged $\times$ Time \\
\hline 19 & DistW $\times$ Time \\
\hline 20 & NDVI $\times$ Time + Slope $\times$ Time \\
\hline 21 & NDVI $\times$ Time + Rugged $\times$ Time \\
\hline 22 & NDVI $\times$ Time + DistW $\times$ Time \\
\hline 23 & Slope $\times$ Time + Rugged $\times$ Time \\
\hline 24 & Slope $\times$ Time + DistW $\times$ Time \\
\hline 25 & Rugged $\times$ Time + DistW $\times$ Time \\
\hline 26 & NDVI $\times$ Time + Slope $\times$ Time + Rugged $\times$ Time \\
\hline 27 & NDVI $\times$ Time + Slope $\times$ Time + DistW $\times$ Time \\
\hline 28 & NDVI $\times$ Time + Rugged $\times$ Time + DistW $\times$ Time \\
\hline 29 & Slope $\times$ Time + Rugged $\times$ Time + DistW $\times$ Time \\
\hline 30 & NDVI $\times$ Time + Slope $\times$ Time + Rugged $\times$ Time + DistW $\times$ Time \\
\hline
\end{tabular}

Covariates considered included vegetation greenness, represented by the Normalised Difference Vegetation Index (NDVI), distance to artificial water points (DistW), slope, terrain ruggedness (Rugged) and time (as represented in Equation 1). In addition, each candidate ruggedness (Rugged) and time (as represented in Equation 1). In addition, each candidate
model included a spline of the distance to previous used location to help reduce bias in step selection function estimation. used to check for the presence of collinearity among covariates in the full model using $\mathrm{R}$ code from Zuur et al. (2009). All VIF values were less than 1.5; therefore, all covariates were retained in the candidate model set. To allow for changing selection over time, candidate models were also run with each covariate interacted with a function of time. Time was included following Equation 3 in Wilson et al. (2014), using a function $F(t)$, defined as:

$$
F(t)=\cos \left(\frac{2 \times \pi \times t}{365}\right)+\sin \left(\frac{2 \times \pi \times t}{365}\right)
$$

where $t$ is the Julian day of an elephant location and its associated available locations. Population-level SSF analyses under each candidate model were run for the six elephants occupying the Main Camp - Colchester section of AENP. Covariate values were scaled by subtracting the mean and dividing by the standard deviation, following the approach of Northrup et al. (2013). Models were run using the 'survival' package in R. Selection between models was performed with the 'AICcmodavg' package in R (Mazerolle 2016), using Akaike's information criterion corrected for small sample size (AICc; Burnham \& Anderson 2002) to select the most parsimonious model.

We followed the approach of Forester et al. (2009) to calculate robust standard errors controlling for multiple observations per individual. This involved calculating deviance residuals for each top model identified through the model selection process, fitting an intercept-only mixed-effects model to the residuals with a random intercept for individual elephants, using the autocorrelation function of this model to determine the lag of correlation, and assigning the data into independent clusters based on the identified lag. The data were subset into two independent models using the clusters and a CLR model was fit on each subset. The resulting covariance matrices from each subset were then averaged to provide adjusted standard errors.

Predictive performance of the top model for each daily data set was assessed both for interpolative ability within the Main Camp - Colchester section of AENP and extrapolative ability using independent data from the collared female elephant in the Nyathi section. Interpolative predictive ability was determined using k-fold cross-validation (Boyce et al. 2002; Johnson et al. 2006), with the used and available data from the six Main Camp - Colchester elephants split 90\% - 10\% across 10 folds. Differences in covariate values in the Nyathi section of AENP compared with the Main Camp - Colchester section (Figures 2-A1 and 3-A1) led to exclusion of the Nyathi elephant from the population-level resource selection model, but provided an opportunity to test model predictive performance in an area with differing availability. Extrapolative predictive ability was evaluated with an adapted version of the Boyce et al. (2002) approach. The top CLR model for each of the three daily data sets was predicted to the Nyathi section of AENP and the resulting values were binned into 10 quantiles. The Spearman's rank correlation between binned values at locations used by 
the Nyathi elephant and the expected number of observations per bin based on the CLR predictions was used to indicate predictive performance.

To visually represent habitat use over time by elephants in AENP, relative habitat suitability was predicted for the Main Camp - Colchester section at a $250 \mathrm{~m}$ resolution following Equation 2 in Wilson et al. (2014):

$$
w(s, t)=\exp \left[\beta \times F(t)^{\prime} \boldsymbol{X}(s, t)\right]
$$

where $\mathrm{w}(s, t)$ is the relative habitat use prediction for pixel $s$ at time $t, \beta$ is the vector of selection coefficients estimated using the procedure above, $F(t)$ follows Equation 1 above and $X(s, t)$ is the vector of environmental covariates measured for pixel $s$ at time $t$. Predicted values were then rescaled using a linear stretch to range between 0 and 1 following Equation 7 in DeCesare et al. (2012):

$$
\hat{w}(s, t)=\left(\frac{w(s, t)-w_{\text {min }}}{w_{\text {max }}-w_{\text {min }}}\right)
$$

Predicted maps of relative elephant use within the Main CampColchester area were estimated for 70 sixteen-day periods, corresponding to the MODIS NDVI composites described above. An aggregated view of the relative probability of elephant use was obtained by averaging each of the 70 predicted maps and applying a linear stretch following Equation 3.

The elephant-accessible areas of AENP are situated within a larger network of sections that together make up the proclaimed national park (Figure 1b). Previous management of elephant numbers in AENP has involved opening new sections of the park to elephants (Kerley \& Landman 2006), as witnessed in the Colchester section during this study. Managers are thus not only interested in how elephants use habitats within currently accessible areas but also in likely movements of elephants if additional fences are removed. To provide a preliminary answer to this question, we used the midday SSF model to predict relative probability of use by elephants across the Greater AENP. Only the midday model was used in this extrapolation because it was the only model to show robust predictions when extrapolated to the Nyathi area (see the Results section).

\section{Results}

The seven collared elephants in this study (six in the Main Camp - Colchester section of AENP plus one in the Nyathi section) each contributed between 504 and 1046 locations to the SSF analyses (Table 1-A2). Depending on the time of the day, elephants exhibited daily steps that averaged between $2151.5 \mathrm{~m}$ and $2267.5 \mathrm{~m}$ (Table 1-A2). Results were similar when the elephant occupying the Nyathi section of AENP was excluded (Table 2-A2).

All three daily movement data sets had clearly supported top models (Table 2). The full model including all covariates and
TABLE 2: Model selection results for elephant resource selection at a daily scale in Addo Elephant National Park, South Africa. Daily selection was considered in the morning (06:00), midday (12:00) and afternoon (16:00) to reflect within-day

\begin{tabular}{|c|c|c|c|}
\hline Model & k & $\triangle \mathrm{AICC}$ & Weight \\
\hline \multicolumn{4}{|l|}{$06: 00$} \\
\hline 30 & 19 & 0.0 & 0.98 \\
\hline 27 & 16 & 8.2 & 0.02 \\
\hline 28 & 16 & 46.3 & 0.00 \\
\hline 22 & 13 & 50.8 & 0.00 \\
\hline 26 & 16 & 64.5 & 0.00 \\
\hline 19 & 11 & 68.0 & 0.00 \\
\hline 20 & 13 & 69.8 & 0.00 \\
\hline 21 & 13 & 110.3 & 0.00 \\
\hline 16 & 10 & 112.3 & 0.00 \\
\hline 18 & 11 & 139.6 & 0.00 \\
\hline 15 & 11 & 140.5 & 0.00 \\
\hline 12 & 10 & 141.0 & 0.00 \\
\hline 13 & 10 & 141.6 & 0.00 \\
\hline 7 & 9 & 141.7 & 0.00 \\
\hline 11 & 10 & 142.8 & 0.00 \\
\hline 5 & 9 & 143.5 & 0.00 \\
\hline 6 & 9 & 143.9 & 0.00 \\
\hline 1 & 8 & 144.2 & 0.00 \\
\hline 29 & 16 & 420.1 & 0.00 \\
\hline 24 & 13 & 448.9 & 0.00 \\
\hline 23 & 13 & 477.5 & 0.00 \\
\hline 25 & 13 & 487.3 & 0.00 \\
\hline 17 & 10 & 499.5 & 0.00 \\
\hline 14 & 10 & 530.7 & 0.00 \\
\hline 8 & 9 & 530.8 & 0.00 \\
\hline 2 & 8 & 536.9 & 0.00 \\
\hline 9 & 9 & 537.1 & 0.00 \\
\hline 10 & 9 & 559.7 & 0.00 \\
\hline 3 & 8 & 560.4 & 0.00 \\
\hline 4 & 8 & 564.0 & 0.00 \\
\hline \multicolumn{4}{|l|}{$12: 00$} \\
\hline 30 & 19 & 0.0 & 1.00 \\
\hline 27 & 16 & 18.4 & 0.00 \\
\hline 28 & 16 & 126.0 & 0.00 \\
\hline 22 & 13 & 145.5 & 0.00 \\
\hline 29 & 16 & 239.8 & 0.00 \\
\hline 24 & 13 & 255.0 & 0.00 \\
\hline 26 & 16 & 285.9 & 0.00 \\
\hline 20 & 13 & 304.4 & 0.00 \\
\hline 21 & 13 & 405.6 & 0.00 \\
\hline 16 & 10 & 425.0 & 0.00 \\
\hline 19 & 11 & 425.2 & 0.00 \\
\hline 25 & 13 & 429.5 & 0.00 \\
\hline 15 & 11 & 478.1 & 0.00 \\
\hline 12 & 10 & 478.9 & 0.00 \\
\hline 14 & 10 & 487.0 & 0.00 \\
\hline 9 & 9 & 487.7 & 0.00 \\
\hline 7 & 9 & 581.4 & 0.00 \\
\hline 13 & 10 & 581.9 & 0.00 \\
\hline 4 & 8 & 611.3 & 0.00 \\
\hline 10 & 9 & 612.0 & 0.00 \\
\hline 23 & 13 & 646.1 & 0.00 \\
\hline 17 & 10 & 662.0 & 0.00 \\
\hline 5 & 9 & 695.4 & 0.00 \\
\hline 11 & 10 & 696.8 & 0.00 \\
\hline
\end{tabular}
variation in selection patterns.

Candidate models were compared using Akaike's information criterion adjusted for small sample size (AICC). The difference in AICC values between models ( $\triangle \mathrm{AICC}$ ), corresponding Akaike weights and the number of parameters retained for each model $(k)$ are reported here. Model numbers correspond to Table 1. 
TABLE 2 (Continues...): Model selection results for elephant resource selection at a daily scale in Addo Elephant National Park, South Africa. Daily selection was considered in the morning (06:00), midday (12:00) and afternoon (16:00) to reflect within-day variation in selection patterns.

\begin{tabular}{|c|c|c|c|}
\hline Model & k & $\triangle \mathrm{AICC}$ & Weight \\
\hline 2 & 8 & 734.3 & 0.00 \\
\hline 8 & 9 & 735.8 & 0.00 \\
\hline 18 & 11 & 782.1 & 0.00 \\
\hline 1 & 8 & 801.7 & 0.00 \\
\hline 6 & 9 & 803.7 & 0.00 \\
\hline 3 & 8 & 882.3 & 0.00 \\
\hline \multicolumn{4}{|l|}{$16: 00$} \\
\hline 30 & 19 & 0.0 & 1.00 \\
\hline 27 & 16 & 24.4 & 0.00 \\
\hline 29 & 16 & 48.5 & 0.00 \\
\hline 24 & 13 & 70.1 & 0.00 \\
\hline 14 & 10 & 109.7 & 0.00 \\
\hline 15 & 11 & 111.6 & 0.00 \\
\hline 28 & 16 & 111.6 & 0.00 \\
\hline 9 & 9 & 123.6 & 0.00 \\
\hline 12 & 10 & 125.5 & 0.00 \\
\hline 22 & 13 & 134.1 & 0.00 \\
\hline 25 & 13 & 174.6 & 0.00 \\
\hline 19 & 11 & 191.1 & 0.00 \\
\hline 13 & 10 & 217.5 & 0.00 \\
\hline 10 & 9 & 222.0 & 0.00 \\
\hline 7 & 9 & 227.9 & 0.00 \\
\hline 4 & 8 & 232.2 & 0.00 \\
\hline 26 & 16 & 284.2 & 0.00 \\
\hline 20 & 13 & 307.9 & 0.00 \\
\hline 23 & 13 & 364.7 & 0.00 \\
\hline 11 & 10 & 380.7 & 0.00 \\
\hline 17 & 10 & 385.8 & 0.00 \\
\hline 5 & 9 & 388.5 & 0.00 \\
\hline 21 & 13 & 389.7 & 0.00 \\
\hline 8 & 9 & 391.9 & 0.00 \\
\hline 2 & 8 & 399.7 & 0.00 \\
\hline 16 & 10 & 412.3 & 0.00 \\
\hline 18 & 11 & 470.5 & 0.00 \\
\hline 6 & 9 & 486.3 & 0.00 \\
\hline 1 & 8 & 491.0 & 0.00 \\
\hline 3 & 8 & 519.7 & 0.00 \\
\hline
\end{tabular}

Candidate models were compared using Akaike's information criterion adjusted for small sample size (AICC). The difference in AICC values between models ( $\triangle \mathrm{AICC}$ ), corresponding Akaike weights and the number of parameters retained for each model $(k)$ are reported here. Model numbers correspond to Table 1.

time-varying selection coefficients (Model 30 in Table 1) was the best for all three data sets, with Akaike weights between 0.98 and 1.00. Selection patterns varied across the daily data sets (Table 3 ), indicating both daily and annual variation in resource selection by female elephants in AENP. Predictive performance of the daily models varied across data sets for both interpolation and extrapolation (Table 3). Interpolative predictive performance, as indicated by $\mathrm{k}$-fold crossvalidation, was high for both the 12:00 and 16:00 daily selection models, while the 06:00 model performed poorly. Extrapolative predictive performance, predicting use for the Nyathi elephant from Main Camp - Colchester resource selection models, showed strong predictive ability at 12:00, but weak performance at 06:00 and 16:00.

We tested four hypotheses of elephant selection based on patterns observed in savanna systems, namely that elephants would show (1) a positive association with vegetation greenness, (2) a negative association with distance to water, (3) a negative association with steeper slopes and (4) a positive association with more rugged terrain. Elephant selection of NDVI varied across the year, with the strongest selection in the winter (July-September) and the least selection in the summer (November-February; Figure 2a). Daily selection of greener vegetation (high NDVI values) in the morning (06:00) was consistently strong across the year, with the exception of February, aligning with the first hypothesis. At midday (12:00), however, selection patterns were more nuanced, with elephants avoiding greener vegetation from mid-November to March and selecting for greener vegetation from late May to September. Elephants showed little selection or avoidance of NDVI in the afternoon (16:00) throughout the year, contrasting with the first hypothesis. Consistent with the second hypothesis, female elephants in AENP tended to select areas closer to water (negative selection coefficient for distance to water), though this varied both diurnally and annually (Figure $2 b$ ). Elephants showed a strong selection for areas near water points in the summer (November-mid-February) at midday and in the afternoon, and the weakest relationship in the morning. Annual patterns in selection coefficients for slope at midday and in the afternoon (Figure 2c) generally supported the third hypothesis, with a predominantly negative relationship that was strongest from October to February and weakest from May to August. Conversely, daily selection patterns in the morning showed little relationship with slope in the summer, but a positive selection for steeper slopes in midwinter (mid-May-mid-July). Variability in selection coefficient values across the year for terrain ruggedness was similar in the morning, midday and afternoon (Figure 2d). While some annual fluctuations in selection were apparent, 95\% confidence intervals for all 3 hours always overlapped zero, indicating little support for selection or avoidance of rugged terrain and contrasting with the fourth hypothesis.

The relative probability of use predicted across the Main Camp - Colchester area using the SSF models varied throughout the day and across the year (Figure 3; Appendix 4). Predicted use in the morning typically emphasised higher probabilities of use in different parts of the park than at midday and noon. On average across the study period, elephant use was predicted to be higher in the southern portions of the elephant-accessible area in the morning and in the northern parts at midday (Figure 4). Use in the afternoon was more evenly distributed across the elephant-accessible area (Figure 4). When extrapolated to the Greater AENP, the midday model predicted the highest probabilities of use in the currently available areas of Main Camp and Colchester as well as the botanical reserves and southern portion of Nyathi (Figure 5). Predicted use was also relatively high in the northernmost portion of the park around Darlington Dam. The central areas of AENP tended to exhibit lower relative probabilities of use according to the midday model.

\section{Discussion}

Our findings are consistent with our first three hypotheses in that elephants in Subtropical Thicket responded 
TABLE 3: Step selection function regression coefficients and associated standard errors for elephants in Addo Elephant National Park at a daily scale, recorded in the morning (06:00), midday (12:00) and afternoon (16:00)

\begin{tabular}{|c|c|c|c|c|c|c|}
\hline \multirow[t]{2}{*}{ Covariate } & \multicolumn{2}{|c|}{ Daily steps at 06:00 } & \multicolumn{2}{|c|}{ Daily steps at $12: 00$} & \multicolumn{2}{|c|}{ Daily steps at $16: 00$} \\
\hline & Coefficient & Standard error & Coefficient & Standard error & Coefficient & Standard error \\
\hline NDVI & 0.625 & \pm 0.066 & 0.006 & \pm 0.033 & 0.016 & \pm 0.041 \\
\hline NDVI.c & -0.126 & \pm 0.076 & -0.496 & \pm 0.062 & -0.198 & \pm 0.069 \\
\hline NDVI.s & -0.089 & \pm 0.106 & -0.118 & \pm 0.064 & -0.129 & \pm 0.047 \\
\hline DistW & -0.042 & \pm 0.103 & -0.598 & \pm 0.162 & -0.652 & \pm 0.148 \\
\hline DistW.c & -0.535 & \pm 0.117 & -0.581 & \pm 0.180 & -0.287 & \pm 0.166 \\
\hline DistW.s & -0.077 & \pm 0.074 & 0.012 & \pm 0.140 & 0.120 & \pm 0.123 \\
\hline Slope & 0.075 & \pm 0.055 & -0.361 & \pm 0.088 & -0.343 & \pm 0.059 \\
\hline Slope.c & -0.333 & \pm 0.076 & -0.242 & \pm 0.083 & -0.127 & \pm 0.086 \\
\hline Slope.s & 0.080 & \pm 0.061 & 0.089 & \pm 0.064 & 0.092 & \pm 0.064 \\
\hline Rugged & -0.229 & \pm 0.193 & 0.116 & \pm 0.142 & 0.247 & \pm 0.175 \\
\hline Rugged.c & 0.362 & \pm 0.305 & 0.186 & \pm 0.172 & 0.063 & \pm 0.197 \\
\hline Rugged.s & 0.241 & \pm 0.177 & 0.404 & \pm 0.173 & 0.333 & \pm 0.158 \\
\hline DistPrev1 & 0.627 & \pm 0.137 & 0.810 & \pm 0.149 & 0.710 & \pm 0.166 \\
\hline DistPrev3 & 1.699 & \pm 0.356 & 1.880 & \pm 0.247 & 1.764 & \pm 0.269 \\
\hline DistPrev4 & 2.115 & \pm 0.423 & 2.274 & \pm 0.306 & 2.208 & \pm 0.317 \\
\hline DistPrev5 & 2.595 & \pm 0.500 & 2.727 & \pm 0.426 & 2.679 & \pm 0.422 \\
\hline DistPrev6 & 3.115 & \pm 0.600 & 3.196 & \pm 0.571 & 3.155 & \pm 0.572 \\
\hline DistPrev7 & 3.640 & \pm 0.715 & 3.667 & \pm 0.730 & 3.631 & \pm 0.742 \\
\hline \multicolumn{7}{|c|}{ Predictive performance } \\
\hline Interpolative & 0.37 & $p=0.219$ & 0.87 & $p<0.001$ & 0.91 & $p<0.001$ \\
\hline Extrapolative & 0.22 & $p=0.537$ & 0.82 & $p=0.007$ & 0.42 & $p=0.232$ \\
\hline
\end{tabular}

Covariate names follow Table 1. Coefficients interacted with time are indicated by .c or .s, corresponding to their interaction with the cosine or sine time-wave function, respectively. The DistPrev1-7 covariates report the coefficient values from the distance to previous location spline. Standard errors reflect Forester et al. (2009)'s adjustment for serial autocorrelation. Values in bold indicate that the coefficient's $95 \%$ confidence interval does not overlap zero. Interpolative predictive performance reflects the mean Spearman's rank correlation using k-fold cross-validation in the Main Camp - Colchester area. P-values for each fold were combined using Fisher's method. Extrapolative ability reflects the Spearman rank correlation between use by the Nyathi elephant and predictions from the Main Camp - Colchester model. See text for details.

positively to feeding opportunities (vegetation greenness) and water and negatively to slope. This provides some confidence in the ability to extrapolate findings between biomes in terms of resource selection by elephants. The fourth hypothesis of a positive association of elephants with more rugged terrain was not supported. The latter hypothesis was predicated upon patterns of increased nutrient distribution being associated with rugged terrain in savanna landscapes (Nellemann et al. 2002). The lack of support for this hypothesis was expected on the basis of the generally high nutrients in Subtropical Thicket soils (Kerley \& Landman 2006). Hence, given the oligotrophic nature of many savanna soils (East 1984), the lack of success in extrapolating this pattern between biomes likely reflects a biome-scale difference rather than a change in elephant resource selection.

There is increasing recognition of the importance of understanding dynamic patterns both in animal movement (Bowler \& Benton 2005; Mueller \& Fagan 2008) and resource selection (McLoughlin et al. 2010). Animals occupying dynamic environments face substantial variability at multiple spatial and temporal scales to which they must respond if they are to obtain the necessary resources to survive and reproduce. The interaction of these changes in environmental conditions and individual behavioural responses results in larger patterns of population-level movement and distribution (Mueller \& Fagan 2008). Understanding the drivers of these space use patterns enables managers to incorporate spatiotemporal patterns of species distribution and impacts into their conservation decisions seeking to balance multiple objectives. Our results indicate that female elephants in AENP exhibit dynamic patterns of resource selection at both daily and annual scales.

Analysis of elephant selection for green vegetation, distance to water and slope indicates variable selection patterns over time both annually and daily. Annual variability in resource selection (Evans \& Harris 2012; Jachowski, Slotow \& Millspaugh 2012; Shannon et al. 2006), movement patterns (Leggett 2010; Loarie et al. 2009a; Wittemyer et al. 2008) and home range size (Osborn 2003; Shannon et al. 2006) has been previously reported for elephants, though typically in the context of seasonal systems. Our study shows that in the aseasonal context of AENP, elephants also show variable selection patterns across the year. For NDVI, distance to water and slope, the most notable divergences from the hypotheses of selection based on patterns seen in savanna systems occur during the winter (approximately MayOctober; Figure 2). While rainfall patterns are aseasonal in AENP, temperature follows much more consistent patterns, with the winter generally being cooler than the summer (Figure 1-A1). Ambient temperature influences habitat selection in elephants (Kinahan, Pimm \& Van Aarde 2007). The cooler temperatures in the winter may relax the need for elephants to remain close to water, allowing them to select for areas of greener vegetation as seen in the positive midday selection coefficients for NDVI during this period.

Daily variation in elephant movement and resource selection is apparent in many systems (e.g. Cook, Henley \& Parrini 2015; Galanti et al. 2006; Graham et al. 2009). These patterns, 


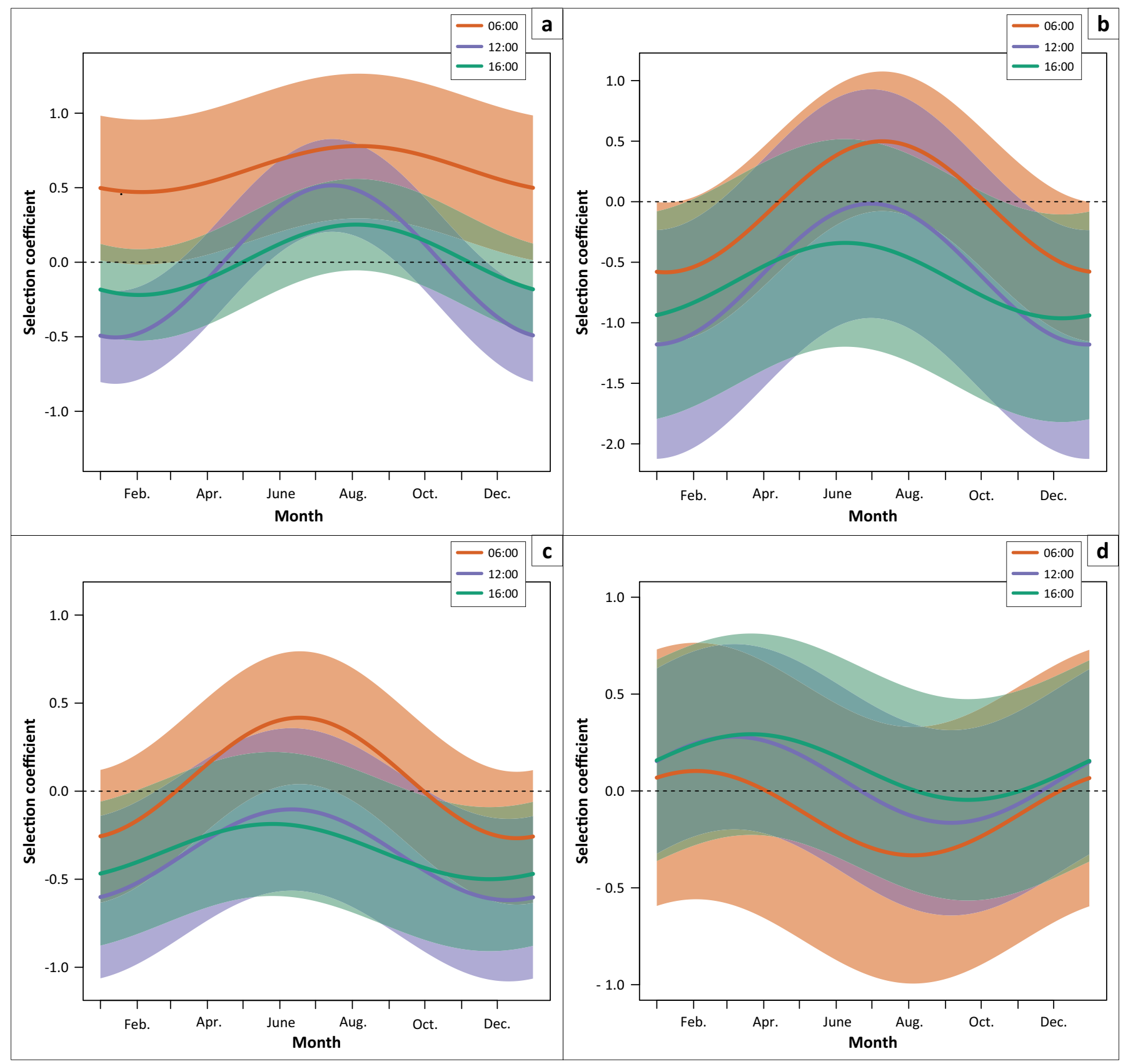

The horizontal dashed line indicates no selection.

Periods of the year where the confidence interval intersects this line have a lack of support for selection or avoidance of that resource. Note that the $y$-axes vary across panels.

FIGURE 2: Plots of annual coefficient estimates (lines) and their $95 \%$ confidence intervals (shaded regions) derived from step selection functions of daily elephant movements recorded at 06:00 (red), 12:00 (blue) and 16:00 (green) for (a) the Normalised Difference Vegetation Index, (b) distance to artificial water, (c) slope and (d) terrain ruggedness.

however, are typically associated with human activity and perceptions of risk by elephants (but see Loarie et al. 2009a). While previous studies often break daily patterns into daynight comparisons, we record finer levels of variability, with selection patterns in the morning often differing from those observed at midday and in the afternoon. This is most pronounced in the selection of green vegetation, but is also somewhat apparent for distance to water and slope. Boettiger et al. (2011) suggest that elephant foraging strategies in seasonal savannas of northern Kenya are more complex than simply selecting areas with the highest productivity, as has been indicated elsewhere (e.g. Loarie et al. 2009b; Wall et al.
2013). Our study finds similar complexity of selection in the aseasonal system of AENP, where elephants consistently select for greener vegetation (higher NDVI values) in the morning, but exhibit negative or neutral selection patterns later in the day. A trade-off has been noted for many herbivores between balancing water requirements and nutritional needs (e.g. Chamaillé-Jammes et al. 2013; Redfern et al. 2003). For elephants, the need to regularly access drinking water (Chamaillé-Jammes et al. 2013) constrains habitat use options (Redfern et al. 2003), limiting the ability of elephants to consistently select for green vegetation. While the small size of AENP and relative frequency of water points 


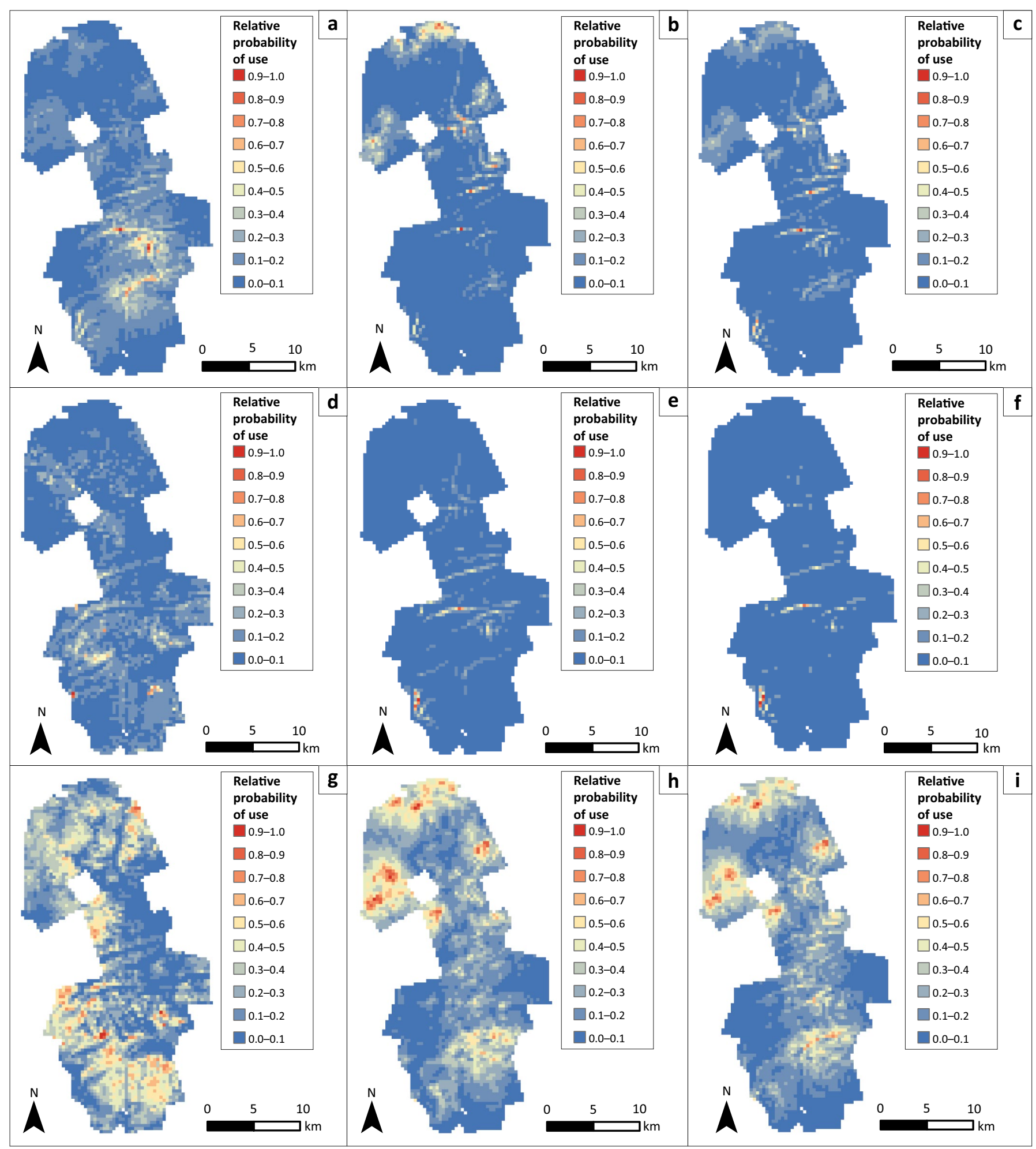

For an animation of predicted use across the entire study period, see Appendix 4.

FIGURE 3: Predicted use by elephants in Addo Elephant National Park on three representative dates throughout the study period (rows) and for the three times of day considered (columns). (a) 01 January 2011, 06:00, (b) 01 January 2011, 12:00, (c) 01 January 2011, 16:00, (d) 23 April 2011, 06:00, (e) 23 April 2011, 12:00, (f) 23 April 2011, 16:00, (g) 30 September 2011, 06:00, (h) 30 September 2011, 12:00, (i) 30 September 2011, 16:00.

in the elephant-accessible areas mean that water is not limiting in the traditional sense of a lack of sufficient water, the localisation of available water interacting with the regular need to access water by elephants may still constrain movement decisions. Indeed, water can still serve as a constraining factor even in systems with very high water availability (Redfern et al. 2003). In AENP, we propose that the concentration of available water at borehole-fed artificial water points leads elephants to function like central-place foragers, as has been seen for other species (Rozen-Rechels et al. 2015). Elephants may venture away from water points in the morning, seeking to maximise their forage intake and meet their nutritional requirements, before returning to water points in the middle of the day. This could explain the 


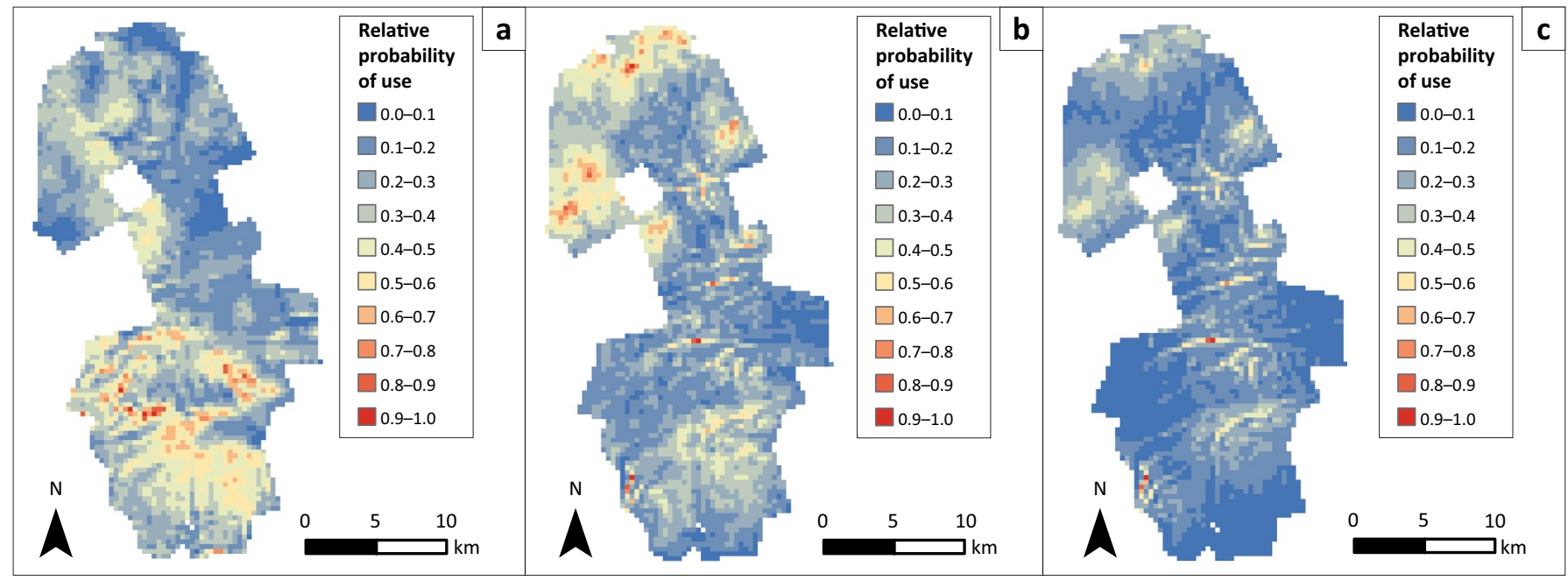

FIGURE 4: Average relative probability of use by elephants in Addo Elephant National Park. Maps reflect the predicted relative probability of use in (a) the morning (06:00), (b) midday (12:00) and (c) afternoon (16:00), averaged across the 70 sixteen-day periods corresponding to the Moderate Resolution Imaging Spectroradiometer composites.

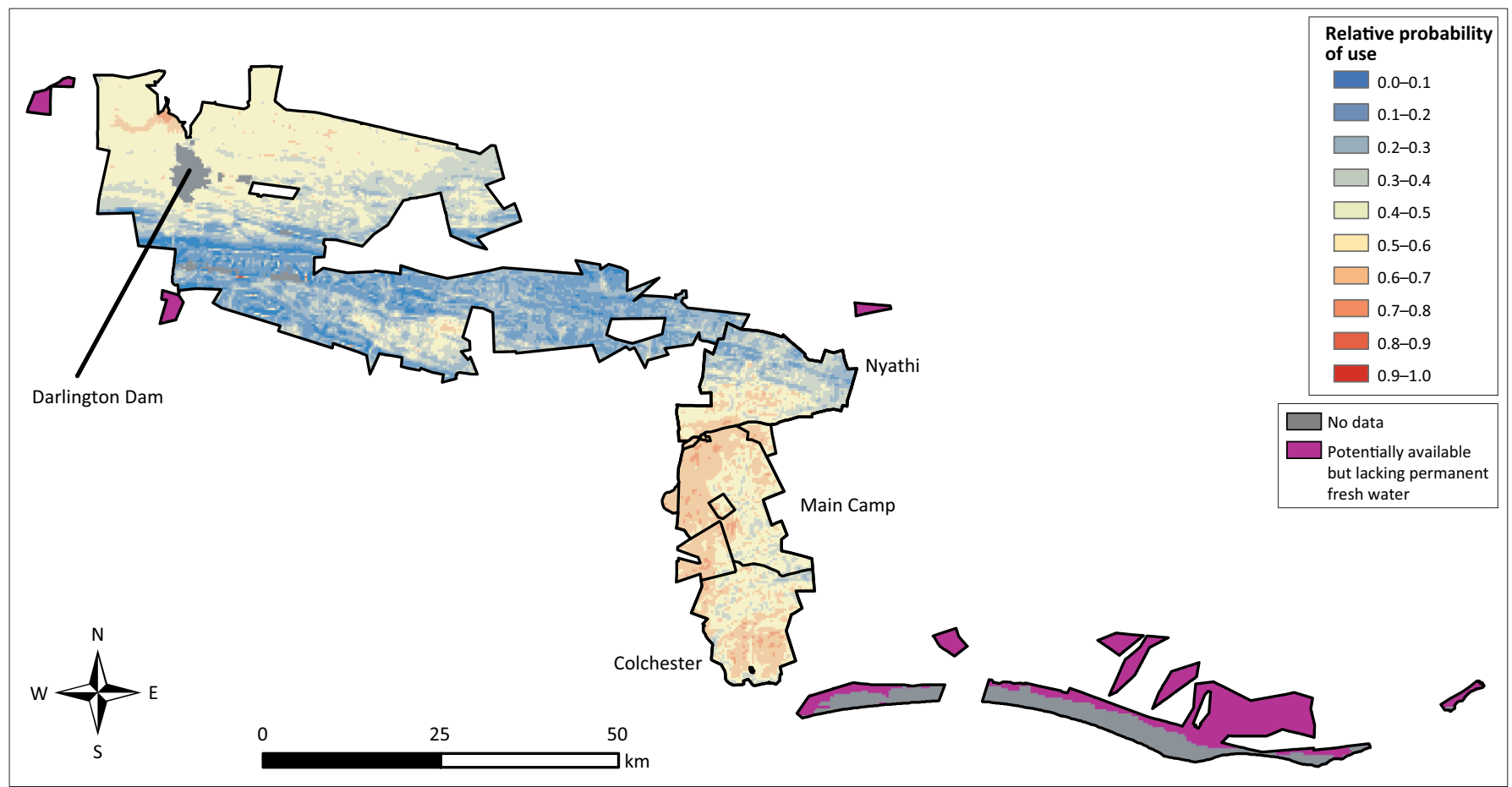

Areas of 'no data' represent locations dominated by water, such as Darlington Dam in the north and the coastline of the Indian Ocean in the south, as well as areas with Moderate Resolution Imaging Spectroradiometer pixel reliability values greater than 1.

Areas in purple fall within Addo Elephant National Park but currently lack permanently available fresh water, making them unsuitable for elephant use.

For an animation of predicted use across the entire study period, see Appendix 4.

FIGURE 5: Relative probability of use by elephants across Addo Elephant National Park. The map reflects the predicted relative probability of use based on the midday (12:00) step selection function model, averaged across the 70 sixteen-day periods corresponding to the Moderate Resolution Imaging Spectroradiometer composites used in this study.

generally positive selection for greener vegetation and weaker relationship with distance to water observed in the morning data. As a generalist forager (Kerley \& Landman 2006), elephants may use a variety of habitats to meet their nutritional requirements. However, the finite water availability in AENP leads to similar patterns of use when drinking, as common targets constrain resource selection strategies (Boettiger et al. 2011). This diversity of options for elephant use in the morning may explain why the morning SSF model had substantially poorer interpolative prediction ability compared with the midday and afternoon models.
In addition to elephants balancing forage-water trade-offs through daily variability in habitat use, they may be able to further minimise trade-offs through habitat modification. High elephant utilisation around artificial water points leads to changes in vegetation structure and composition, with succulent thicket vegetation being largely replaced by grass (Landman et al. 2012). O'Connor, Goodman and Clegg (2007) suggested that elephants should favour green grasses and forbs as a food source because of their high potential intake rate. Dietary studies indicate this is the case in AENP, as Cynodon dactylon, the main grass growing around highly 
utilised water points (Landman et al. 2012), comprises a significant proportion of elephant diet (Landman et al. 2008; Paley \& Kerley 1998). Elephants thus may be creating favourable conditions that enhance their forage opportunities, similar to patterns seen in other systems (Du Toit \& Olff 2014). These modified areas may allow elephants to meet their water requirement while minimising their cost in reduced forage opportunities.

All location data in this study are for female elephants. Patterns may differ for male elephants, as studies from various parts of southern Africa have found behavioural, diet and movement differences between sexes (Evans \& Harris 2012; Shannon, Mackey \& Slotow 2013; Smit, Grant \& Whyte 2007b). Similarly, Whitehouse and Schoeman (2003) reported differences between female and male elephant movement patterns in AENP. In addition, Duffy et al. (2011) suggested that sexual activity may alter elephant movement patterns, even overriding the importance of factors such as water. It is unclear what influence male elephants in AENP may have had on female movement and habitat selection or how the patterns described here for female herds reflect habitat selection decisions made by males. However, GPS collars were recently placed on several male elephants in AENP (A. Gaylard, unpublished data), enabling future comparison of habitat selection patterns for male elephants with those observed here.

\section{Management implications}

Balancing the objectives of protecting biodiversity and enhancing tourist experiences and outcomes is a key challenge for conservation in protected areas worldwide. In some cases, a desire to improve tourist outcomes leads to managers increasing numbers of charismatic species. In AENP, this has meant introducing lions (Panthera leo; SANParks 2008), while other South African parks and reserves stock high densities of lions, cheetahs (Acinonyx jubatus) and elephants (Clements, Cumming \& Kerley 2016; Maciejewski \& Kerley 2014). At high densities, however, elephants have negative impacts on the vegetation and animals of AENP (Kerley \& Landman 2006; Landman \& Kerley 2014; Landman et al. 2008; Tambling et al. 2013), threatening the rare plants contained within the park and compromising the mandate of SANParks to protect biodiversity. Fortunately, recent analyses suggest that high elephant densities may not be necessary to produce positive tourist experiences (Maciejewski \& Kerley 2014). This provides an opportunity to promote 'smarter tourism', improving viewing success by guiding tourists towards areas where they are likely to see elephants, rather than by increasing elephant numbers artificially. The results of this and other similar studies can inform such efforts, providing daily and annual guidance on elephant space use patterns that can help visitors' planning. For example, our SSF models suggest that areas around water points may not provide the best viewing opportunities for early morning tourism. Tourists should visit other areas of the park in the morning or focus on other species during this period. By midday, the probability of viewing elephants around water points should increase and should be maintained into the afternoon, though with greater variability. These models can also be used to inform plans to develop tourism infrastructure such as roads that will improve access to elephant-viewing opportunities. It is important to note, however, that these are general trends and that specific patterns of habitat use by elephants may vary at different times of the year as elephants respond to other factors such as ambient temperature or rainfall (Birkett et al. 2012).

In AENP, as in many other small fenced reserves in South Africa (Mackey et al. 2006; Slotow et al. 2005), the elephant population has grown rapidly over time, often exceeding the estimated carrying capacity of the elephant-accessible areas (Gough \& Kerley 2006; Hayward \& Kerley 2009). One way managers have addressed increasing elephant numbers in AENP is by opening new areas to elephants, temporarily reducing overall density (Gough \& Kerley 2006). Our projections of the relative probability of elephant use across the Greater AENP (Figure 5) offer insights into where elephant use may concentrate if given access to new areas. As expected, the areas currently available to elephants in Main Camp, Colchester and the southern portion of Nyathi show high likelihood of continued use by elephants. The use of these areas by elephants is likely to remain high even if other areas are made available because of the long-term spatiotemporal memory of elephants (Van Aarde et al. 2008), which enables social transmission of site fidelity across generations (Fishlock, Caldwell \& Lee 2016). The botanical reserves and other fenced areas in the Main Camp and Colchester sections are explicitly included in our forecasts and, as expected, show an overall high likelihood of use by elephants, emphasising their importance in protecting rare plants from elephant impacts (Lombard et al. 2001). Other areas that are included in the Greater AENP but currently lack permanent water (shown in purple in Figure 5) could be made available to elephants if artificial water points are established, as they have been in Main Camp, Colchester and Nyathi. Managers can use our resource selection model to test the effects of potential water point placement on predicted probabilities of elephant use in these disconnected areas to assess their suitability for elephant introduction.

We note that although the extrapolative validation of the midday SSF model showed it to be robust to making predictions under different resource availability in the Nyathi section, this does not guarantee that the observed relationships will be maintained elsewhere across the Greater AENP. This may especially be true if elephants modify existing habitats as noted above, which could alter the probability of elephant use in some areas. In addition, our analyses show that elephant resource selection and habitat use patterns in AENP vary throughout the day; thus, maps generated based on midday selection relationships may not reflect the relative probability of use by elephants at all hours of the day. Our predictions should be treated as hypotheses of future use by elephants. Field verification is required to determine how elephant use actually conforms to model 
predictions as access is expanded. These observations will reveal how vegetation communities change as elephants move into areas from which they have long been absent and may suggest whether additional botanical reserves need to be established to protect rare plants from elephant impacts.

\section{Conclusion}

Behavioural trade-offs are common in nature. We find this to be true for female elephants in the aseasonal system of AENP, which employ dynamic patterns of resource selection at daily and annual scales to meet their competing requirements for forage, water and other resources. In the summer, selection patterns for vegetation productivity (NDVI), distance to water and slope generally conform to those exhibited by elephants in savanna systems, but these relationships become weaker or reversed in the winter. At daily scales, resource selection by elephants varies in the morning from patterns seen at midday and in the afternoon, likely reflecting temporal reactions of elephants to the trade-off between acquiring sufficient forage and water. These results reinforce the importance of considering dynamic resources in studies of animal selection (McLoughlin et al. 2010). For elephants, future research should expand consideration of daily variability in movement and resource selection from situations relating to human-elephant conflict to consider other aspects of resource use.

Protected area managers also seek to balance trade-offs between competing objectives. In AENP, managers must weigh trade-offs between the desires of tourists and the conservation needs of elephants, rare plants and other elements of biodiversity. Our findings provide an opportunity to promote 'smarter tourism', improving viewing success by guiding tourists towards areas where they are likely to see elephants and improving tourist access infrastructure in such areas, rather than by increasing elephant numbers. In general, areas near waterholes are likely to be highly utilised by elephants at midday and in the afternoon, offering rewarding tourist viewing opportunities, but are less likely to be used by elephants in the morning. The results also offer insights into possible effects of future expansion of elephant access in AENP, predicting where elephant use may concentrate if elephants are given access to new areas. Such information can suggest priorities for detailed assessment of vegetation communities to determine where key areas of rare plants occur prior to elephant access. Such information may allow establishment of new botanical reserves, helping protect plants from elephant impacts and improving the likelihood of sustainable outcomes in the park.

\section{Acknowledgements}

The authors would like to thank South African National Parks (SANParks) for providing permission, data and support for this project, especially to Z. Silcock. M. Landman provided helpful background about AENP and its elephants. P. Bradshaw and I. Smit provided GIS data for AENP. R. Wilson and D. Gregovich offered helpful suggestions and
$\mathrm{R}$ code that improved the analysis. Funding was provided by the Cleveland Metroparks Zoo and Cleveland Zoological Society, National Science Foundation Grant No. 0801544 and NASA Project NNX09AI25G. The Wilderness Society provided support to T.J.F. for the writing of this article. The funders of this work provided financial support but had no role in study design, data collection, analysis or interpretation of results. These actions and the decision to publish were solely at the discretion of the authors. R. Fletcher and three anonymous reviewers provided helpful comments on previous versions of this article. J. Steele facilitated formation of collaborative research between SANParks, the University of Florida and Nelson Mandela Metropolitan University.

\section{Competing interests}

The authors declare that they have no financial or personal relationships that may have inappropriately influenced them in writing this article.

\section{Authors' contributions}

T.J.F. was the project leader and designed and conducted the analysis. A.G. and G.I.H.K. provided elephant telemetry data and offered insightful revisions of the article. P.W. provided guidance with analysis and a thorough revision of the article. G.A.K. and J.S. supervised the project and contributed to the writing and revision of the article.

\section{References}

Beyer, H.L., Haydon, D.T., Morales, J.M., Frair, J.L., Hebblewhite, M., Mitchell, M. et al., 2010, 'The interpretation of habitat preference metrics under use-availability designs', Philosophical Transactions of the Royal Society B 365, 2245-2254. https://doi.org/10.1098/rstb.2010.0083

Birkett, P.J., Vanak, A.T., Muggeo, V.M.R., Ferreira, S.M. \& Slotow, R., 2012, 'Animal perception of seasonal thresholds: Changes in elephant movement in relation to rainfall patterns', PLoS One 7(6), e38363. https://doi.org/10.1371/journal. pone. 0038363

Boettiger, A.N., Wittemyer, G., Starfield, R., Volrath, F., Douglas-Hamilton, I. \& Getz, W.M., 2011, 'Inferring ecological and behavioral drivers of African elephant movement using a linear filtering approach', Ecology 92(8), 1648-1657. https:// doi.org/10.1890/10-0106.1

Boshoff, A.F., Landman, M., Kerley, G.I.H. \& Bradfield, M., 2007, 'Profiles, views and observations of visitors to the Addo Elephant National Park, Eastern Cape, South Africa', South African Journal of Wildlife Research 37, 189-196. https://doi. org/10.3957/0379-4369-37.2.189

Bowler, D.E. \& Benton, T.G., 2005, 'Causes and consequences of animal dispersal strategies: Relating individual behaviour to spatial dynamics', Biological Review 80, 205-225. https://doi.org/10.1017/\$1464793104006645

Boyce, M.S., 2006, 'Scale for resource selection functions', Diversity and Distributions 12, 269-276. https://doi.org/10.1111/j.1366-9516.2006.00243.x

Boyce, M.S., Vernier, P.A., Nielsen, S.E. \& Schmiegelow, F.K.A., 2002, 'Evaluating resource selection functions', Ecological Modelling 157, 281-300. https://doi. org/10.1016/S0304-3800(02)00200-4

Burnham, K.P. \& Anderson, D.R., 2002, Model selection and multimodel inference: $A$ practical information-theoretic approach, 2nd edn., Springer-Verlag, New York.

Calenge, C., 2006, 'The package adehabitat for the R software: A tool for the analysis of space and habitat use by animals', Ecological Modelling 197, 516-519. https:// doi.org/10.1016/j.ecolmodel.2006.03.017

Chamaillé-Jammes, S., Mtare, G., Makuwe, E. \& Fritz, H., 2013, 'African elephants adjust speed in response to surface-water constraint on foraging during the dryseason', PLoS One 8(3), e59164. https://doi.org/10.1371/journal.pone.0059164

Chamaillé-Jammes, S., Valeix, M. \& Fritz, H., 2007, 'Managing heterogeneity in elephant distribution: Interactions between elephant population density and surface-water availability', Journal of Applied Ecology 44, 625-633. https://doi. org/10.1111/j.1365-2664.2007.01300.x

Clements, H.S., Cumming, G.S. \& Kerley, G.I.H., 2016, 'Predators on private land: Broad-scale socioeconomic interactions influence large predator management', Ecology and Society 21(2), 45. https://doi.org/10.5751/ES-08607-210245 
Cook, R.M., Henley, M.D. \& Parrini, F., 2015, 'Elephant movement patterns in relation to human inhabitants in and around the Great Limpopo Transfrontier Park', to human inhabitants in and
Koedoe 57(1), Art. \#1298, 1-7.

D'Eon, R.G. \& Delparte, D., 2005, 'Effects of radio-collar position and orientation on GPS radio-collar performance, and the implications of PDOP in data screening' Journal of Applied Ecology 42, 383-388. https://doi.org/10.1111/j.1365-2664. 2005.01010.x

DeCesare, N.J., Hebblewhite, M., Schmiegelow, F., Hervieux, D., McDermid, G.J., Neufeld, L. et al., 2012, 'Transcending scale dependence in identifying habitat with resource selection functions', Ecological Applications 22, 1068-1083. https:// doi.org/10.1890/11-1610.1

Duchesne, T., Fortin, D. \& Courbin, N., 2010, 'Mixed conditional logistic regression for habitat selection studies', Journal of Animal Ecology 79, 548-555. https://doi. org/10.1111/j.1365-2656.2010.01670.

Duffy, K.J., Dai, X., Shannon, G., Slotow, R. \& Page, B., 2011, 'Movement patterns of African elephants (Loxodonta africana) in different habitat types', South African Journal of Wildlife Research 41, 21-28. https://doi.org/10.3957/056.041.0107

Du Toit, J. \& Olff, H., 2014, 'Generalities in grazing and browsing ecology: Using acrossguild comparisons to control contingencies', Oecologia 174, 1075-1083. https:// doi.org/10.1007/s00442-013-2864-8

East, R., 1984, 'Rainfall, soil nutrient status and biomass of large African savanna mammals', African Journal of Ecology 22, 245-270. https://doi.org/ mammals', African Journal of
10.1111/j.1365-2028.1984.tb00700.x

Evans, K. \& Harris, S., 2012, 'Sex differences in habitat use by African elephants (Loxodonta africana) in the Okavango Delta, Botswana: Is size really the deciding factor?', African Journal of Ecology 50, 277-284. https://doi.org/10.1111/j.13652028.2012.01322.x

Ferreira, S., Freitag-Ronaldson, S., Pienaar, D. \& Hendriks, H., 2011, Elephant management plan: Addo Elephant National Park 2011-2020, Scientific Services, South African National Parks, Skukuza, South Africa.

Fishlock, V., Caldwell, C. \& Lee, P.C., 2016, 'Elephant resource-use traditions', Animal Cognition 19, 429-433. https://doi.org/10.1007/s10071-015-0921-x

Forester, J.D., Im, H.K. \& Rathouz, P.J., 2009, 'Accounting for animal movement in estimation of resource selection functions: Sampling and data analysis', Ecology 90, 3554-3565. https://doi.org/10.1890/08-0874.1

Fortin, D., Beyer, H.L., Boyce, M.S., Smith, D.W., Duchesne, T. \& Mao, J.S., 2005, 'Wolves influence elk movements: Behaviour shapes a trophic cascade in Yellowston National Park', Ecology 86, 1320-1330. https://doi.org/10.1890/04-0953

Galanti, V., Preatoni, D., Martinoli, A., Wauters, L.A. \& Tosi, G., 2006, 'Space and habitat use of the African elephant in the Tarangire-Manyara ecosystem, Tanzania: habitat use of the African elephant in the Tarangire-Manyara ecosystem, Tanzania:
Implications for conservation', Mammalian Biology 7, 99-114. https://doi. org/10.1016/j.mambio.2005.10.001

Gough, K.F. \& Kerley, G.I.H., 2006, 'Demography and population dynamics in the elephants Loxodonta africana of Addo Elephant National Park, South Africa: Is there evidence of density dependent regulation?', Oryx 40, 434-441. https://doi. org/10.1017/S0030605306001189

Graham, M.D., Douglas-Hamilton, I., Adams, W.M. \& Lee, P.C., 2009, 'The movement of African elephants in a human-dominated land-use mosaic', Animal Conservation 12, 445-455. https://doi.org/10.1111/j.1469-1795.2009.00272.x

Hall-Martin, A., 1980, 'Elephant survivors', Oryx 15, 355-362. https://doi.org/10.1017/ S0030605300028830

Hayward, M.W. \& Kerley, G.I.H., 2009, 'Fencing for conservation: Restriction of evolutionary potential or a riposte to threatening processes?', Biological Conservation 142, 1-13. https://doi.org/10.1016/j.biocon.2008.09.022

Hirsch, P.D., Adams, W.M., Brosius, J.P., Zia, A., Bariola, N. \& Dammert, J.L., 2011 'Acknowledging conservation trade-offs and embracing complexity', Conservation Biology 25, 259-264.

Hopcraft, J.G.C., Olff, H. \& Sinclair, A.R.E., 2010, 'Herbivores, resources and risks: Alternating regulation along primary environmental gradients in savannas', Trends in Ecology and Evolution 25, 119-128. https://doi.org/10.1016/j.tree.2009.08.001

Huete, A., Didan, K., Van Leeuwen, W., Miura, T. \& Glenn, E., 2011, 'MODIS vegetation indices', in B. Ramachandran, C.O. Justice \& M.J. Abrams (eds.), Land remote sensing and global environmental change: NASA's Earth Observing System and the sensing and global environmental change: NASA's Earth Observing
Science of ASTER and MODIS, pp. 579-602, Springer, New York.

Huete, A., Justice, C. \& Van Leeuwen, W., 1999, MODIS vegetation index (MOD 13): Algorithm theoretical basis document, Version 3, USGS Land Process Distributed Active Archive Center, viewed 04 December 2012, from http://www.modis.gsfc. nasa.gov/data/atbd/atbd_mod13.pdf

Jachowski, D.S., Slotow, R. \& Millspaugh, J.J., 2012, 'Physiological stress and refuge behavior by African elephants', PLoS One 7(2), e31818. https://doi.org/10.1371/ journal.pone.0031818

Johnson, C.J., Nielsen, S.E., Merrill, E.H., McDonald, T.L. \& Boyce, M.S., 2006, 'Resource selection functions based on use-availability data: Theoretical motivation and evaluation methods', Journal of Wildlife Management 70, 347-357. https://doi. org/10.2193/0022-541X(2006)70[347:RSFBOU]2.0.CO;2

Kerley, G.I.H. \& Boshoff, A., 1997, 'A proposal for a Greater Addo National Park: A regional and national conservation and development opportunity', Terrestria Ecology Research Unit Report 17, University of Port Elizabeth, Port Elizabeth, South Africa.

Kerley, G.I.H. \& Landman, M., 2006, 'The impacts of elephants on biodiversity in the Eastern Cape subtropical thickets', South African Journal of Science 102, 395-402.

Kinahan, A.A., Pimm, S.L. \& Van Aarde, R.J., 2007, 'Ambient temperature as a determinant of landscape use in the savanna elephant, Loxodonta africana', Journa of Thermal Biology 32, 47-58. https://doi.org/10.1016/j.jtherbio.2006.09.002
Landman, M. \& Kerley, G.I.H., 2014, 'Elephant both increase and decrease availability of browse resources for black rhinoceros', Biotropica 46, 42-49. https://doi. org/10.1111/btp.12066

Landman, M., Kerley, G.I.H. \& Schoeman, D.S., 2008, 'Relevance of elephant herbivory as a threat to important plants in the Addo Elephant National Park, South Africa', Journal of Zoology 274, 51-58.

Landman, M., Schoeman, D.S., Hall-Martin, A.J. \& Kerley, G.I.H., 2012, 'Understanding long-term variations in an elephant piosphere effect to manage impacts', PLoS One 7(9), e45334.

Leggett, K., 2010, 'Daily and hourly movement of male desert-dwelling elephants', African Journal of Ecology 48, 197-205. https://doi.org/10.1111/j.1365-2028. 2009.01101.x

Loarie, S.R., Van Aarde, R.J. \& Pimm, S.L., 2009a, 'Fences and artificial water affect African savannah elephant movement patterns', Biological Conservation 142 3086-3098. https://doi.org/10.1016/j.biocon.2009.08.008

Loarie, S.R., Van Aarde, R.J. \& Pimm, S.L., 2009b, 'Elephant seasonal vegetation preferences across dry and wet savannas', Biological Conservation 142, 3099 3107. https://doi.org/10.1016/j.biocon.2009.08.021

Lombard, A.T., Johnson, C.F., Cowling, R.M. \& Pressey, R.L., 2001, 'Protecting plants from elephants: Botanical reserve scenarios within the Addo Elephant National Park, South Africa', Biological Conservation 102, 191-203. https://doi. Park, South Africa', Biological Conse
org/10.1016/S0006-3207(01)00056-8

Maciejewski, K. \& Kerley, G.I.H., 2014, 'Elevated elephant density does not improve ecotourism opportunities, convergence in social and ecological objectives', Ecological Applications 24, 920-926. https://doi.org/10.1890/13-0935.1

Mackey, R.L., Page, B.R., Duffy, K.J. \& Slotow, R., 2006, 'Modelling elephant population growth in small, fenced, South African reserves', South African Journal of Wildlife Research 36, 33-43.

Manly, B.F.J., McDonald, L.L., Thomas, D.L., McDonald, T.L. \& Erickson, W.P., 2002, Resources selection by animals: Statistical design and analysis for field studies, 2nd edn., Kluwer Academic Publishers, Boston, MA.

Marshal, J.P., Rajah, A., Parrini, F., Henley, M., Henley, S.R. \& Erasmus, B.F.N., 2011, 'Scale-dependent selection of greenness by African elephants in the Krugerprivate reserve transboundary region, South Africa', European Journal of Wildlife Research 57, 537-548. https://doi.org/10.1007/s10344-010-0462-1

Mazerolle, M.J., 2016, AlCcmodavg: Model selection and multimodel inference based on (Q)AIC(c), R package version 2.0-4, viewed 27 April 2016, from http://www. CRAN.R-project.org/package=AICcmodavg

McLoughlin, P.D., Morris, D.W., Fortin, D., Vander Wal, E. \& Contasti, A.L., 2010 'Considering ecological dynamics in resource selection functions', Journal of Animal Ecology 79, 4-12. https://doi.org/10.1111/j.1365-2656.2009.01613.x

McShane, T.O., Hirsch, P.D., Trung, T.C., Songorwa, A.N., Kinzig, A., Monteferri, B. et al., 2011, 'Hard choices: Making trade-offs between biodiversity conservation and
human well-being', Biological Conservation 144, 966-972. https://doi. human well-being', Biological
org/10.1016/j.biocon.2010.04.038

Mueller, T. \& Fagan, W.F., 2008, 'Search and navigation in dynamic environments From individual behaviors to population distributions', Oikos 117, 654-664. https://doi.org/10.1111/j.0030-1299.2008.16291.x

Nellemann, C., Moe, S.R. \& Rutina, L.P., 2002, 'Links between terrain characteristics and forage patterns of elephants (Loxodonta africana) in northern Botswana', Journal of Tropical Ecology 18, 835-844. https://doi.org/10.1017/S026646 7402002547

Northrup, J.M., Hooten, M.B., Anderson, C.R., Jr. \& Wittemyer, G., 2013, 'Practica guidance on characterizing availability in resource selection functions under a use-availability design', Ecology 94, 1456-1463. https://doi.org/10.1890/12 1688.1

O'Connor, T.G., Goodman, P.S. \& Clegg, B., 2007, 'A functional hypothesis of the threat of local extirpation of woody plant species by elephant in Africa', Biological Conservation 136, 329-345. https://doi.org/10.1016/j.biocon.2006.12.014

Osborn, F.V., 2003, 'Seasonal influence of rainfall and crops on home-range expansion by bull elephants', Pachyderm 35, 53-59.

Owen-Smith, N., Kerley, G.I.H., Page, B., Slotow, R. \& Van Aarde, R.J., 2006, 'A scientific perspective on the management of elephants in the Kruger National Park and elsewhere', South African Journal of Science 102, 389-394.

Paley, R.G.T. \& Kerley, G.I.H., 1998, 'The winter diet of elephant in Eastern Cape Subtropical Thicket, Addo Elephant National Park', Koedoe 41, 37-45. https://doi. org/10.4102/koedoe.v41i1.244

Panzacchi, M., Van Moorter, B., Strand, O., Saerens, M., Kivimäki, I., St. Clair, C.C. et al., 2016, 'Predicting the continuum between corridors and barriers to animal movements using step selection functions and randomized shortest paths', Journal of Animal Ecology 85, 32-42. https://doi.org/10.1111/1365-2656.12386

Pettorelli, N., Ryan, S., Mueller, T., Bunnefeld, N., Jędrzejewska, B., Lima, M. et al., 2011, 'The Normalized Difference Vegetation Index (NDVI): Unforeseen successes in animal ecology', Climate Research 46, 15-27. https://doi.org/10.3354/cr00936

Pettorelli, N., Vik, J.O., Mysterud, A., Gaillard, J.-M., Tucker, C.J. \& Stenseth, N.C., 2005, 'Using the satellite-derived NDVI to assess ecological responses to environmental change', Trends in Ecology and Evolution 20, 503-510. https://doi.org/10.1016/ j.tree.2005.05.011

Pittiglio, C., Skidmore, A.K., Van Gils, H.A.M.J. \& Prins, H.H.T., 2012, 'Identifying transit corridors for elephant using a long time-series', International Journal of Applied Earth Observation and Geoinformation 14, 61-72. https://doi.org/10.1016/ j.jag.2011.08.006

R Core Team, 2016, R: A language and environment for statistical computing, R Foundation for Statistical Computing, Vienna, Austria, Version 3.2.4, viewed 13 April 2016, from http://www.R-project.org 
Redfern, J.V., Grant, R., Biggs, H. \& Getz, W.M., 2003, 'Surface-water constraints on herbivore foraging in the Kruger National Park, South Africa', Ecology 84, 20922107. https://doi.org/10.1890/01-0625

Roever, C.L., Van Aarde, R.J. \& Leggett, K., 2012, 'Functional responses in the habitat selection of a generalist megaherbivore, the African savannah elephant', Ecography 35(11), 972-982. https://doi.org/10.1111/j.1600-0587.2012.07359.x

Rozen-Rechels, D., Van Beest, F.M., Richard, E., Uzal, A., Medill, S.A. \& McLoughlin P.D., 2015, 'Density-dependent, central-place foraging in a grazing herbivore: Competition and tradeoffs in time allocation near water', Oikos 124, 1142-1150. https://doi.org/10.1111/oik.02207

SANParks, 2008, Addo Elephant National Park management plan, SANParks, Skukuza, South Africa.

SANParks, 2011, Animal abundances in parks - 2010/2011, SANParks, Skukuza South Africa.

Sappington, J.M., Longshore, K.M. \& Thompson, D.B., 2007, 'Quantifying landscape ruggedness for animal habitat analysis: A case study using bighorn sheep in the Mojave Desert', Journal of Wildlife Management 71, 1419-1426. https://doi. org/10.2193/2005-723

Shannon, G., Mackey, R.L. \& Slotow, R., 2013, 'Diet selection and seasonal dietary switch of a large sexually dimorphic herbivore', Acta Oecologica 46, 48-55. https://doi.org/10.1016/j.actao.2012.10.013

Shannon, G., Matthews, W.S., Page, B.R., Parker, G.E. \& Smith, R.J., 2009, 'The affects of artificial water availability on large herbivore ranging patterns in savann habitats: A new approach based on modelling elephant path distributions Diversity and Distributions 15, 776-783. https://doi.org/10.1111/j.1472-4642. 2009.00581.x

Shannon, G., Page, B., Slotow, R. \& Duffy, K., 2006, 'African elephant home range and habitat selection in Pongola Game Reserve, South Africa', African Zoology 41, 37-44. https://doi.org/10.3377/1562-7020(2006)41[37:AEHRAH]2.0.CO;2

Slotow, R., Garaï, M.E., Reilly, B., Page, B. \& Carr, R.D., 2005, 'Population dynamics of elephants re-introduced to small fenced reserves in South Africa', South African Journal of Wildlife Research 35, 23-32.

Smit, I.P.J., Grant, C.C. \& Whyte, I.J., 2007a, 'Do artificial water holes influence the way herbivores use the landscape? Herbivore distribution patterns around rivers and artificial surface water sources in large African savanna park', Biological Conservation 136, 85-99. https://doi.org/10.1016/j.biocon.2006. 11.009
Smit, I.P.J., Grant, C.C. \& Whyte, I.J., 2007b, 'Landscape-scale sexual segregation in the dry season distribution and resource utilization of elephants in Kruger National Park, South Africa', Diversity and Distributions 13, 225-236. https://doi. org/10.1111/j.1472-4642.2007.00318.x

Tambling, C.J., Minnie, L., Adendorff, J. \& Kerley, G.I.H., 2013, 'Elephants facilitate impact of large predators on small ungulate prey species', Basic and Applied Ecology 14, 694-701. https://doi.org/10.1016/j.baae.2013.09.010

Therneau, T., 2015, 'A package for survival analysis in S. R package version 2.38', viewed 13 April 2016, from http://www.CRAN.R-project.org/package=survival

Therneau, T.M. \& Grambsch, P.M., 2000, Modeling survival data: Extending the Cox model, Springer, New York.

Van Aarde, R., Ferreira, S., Jackson, T., Page, B., De Beer, Y., Gough, K. et al., 2008, 'Elephant population biology and ecology', in R.J. Scholes \& K.G. Mennell (eds.), Elephant management: A scientific assessment of South Africa, pp. 84-145, Witwatersrand University Press, Johannesburg, South Africa.

VRM, 2012, Vector Ruggedness Measure (Terrain Ruggedness) tool, viewed 22 June 2015, from http://www.arcgis.com/home/item.html?id=9e4210b3ee7b413bbb1f 2015, from http://

Wall, J., Douglas-Hamilton, I. \& Vollrath, F., 2006, 'Elephants avoid costly mountaineering', Current Biology 16, 527-529. https://doi.org/10.1016/j.cub.2006.06.049

Wall, J., Wittemyer, G., Klinkenberg, B., LeMay, V. \& Douglas-Hamilton, I., 2013, 'Characterizing properties and drivers of long distance movements by elephants (Loxodonta africana) in the Gourma, Mali', Biological Conservation 157, 60-68. https://doi.org/10.1016/j.biocon.2012.07.019

Whitehouse, A.M. \& Schoeman, D.S., 2003, 'Ranging behaviour of elephants within a small, fenced area in Addo Elephant National Park, South Africa', African Zoology 38, 95-108.

Wilson, R.R., Horne, J.S., Rode, K.D., Regehr, E.V. \& Durner, G.M., 2014, 'Identifying polar bear resource selection patterns to inform offshore development in a dynamic and changing Arctic', Ecosphere 5(10), 136. https://doi.org/10.1890/ES14-00193.1

Wittemyer, G., Polansky, L., Douglas-Hamilton, I. \& Getz, W.M., 2008, 'Disentangling the effects of forage, social rank, and risk on movement autocorrelation of elephants using Fourier and wavelet analyses', Proceedings of the Nationa Academy of Sciences of the United States 109, 19108-19113. https://doi. org/10.1073/pnas.0801744105

Zuur, A.F., leno, E.N., Walker, N.J., Saveliev, A.A. \& Smith, G.M., 2009, Mixed effects models and extensions in ecology with $R$, Springer, New York. 


\section{Appendix 1: Environmental data description for Addo Elephant National Park}
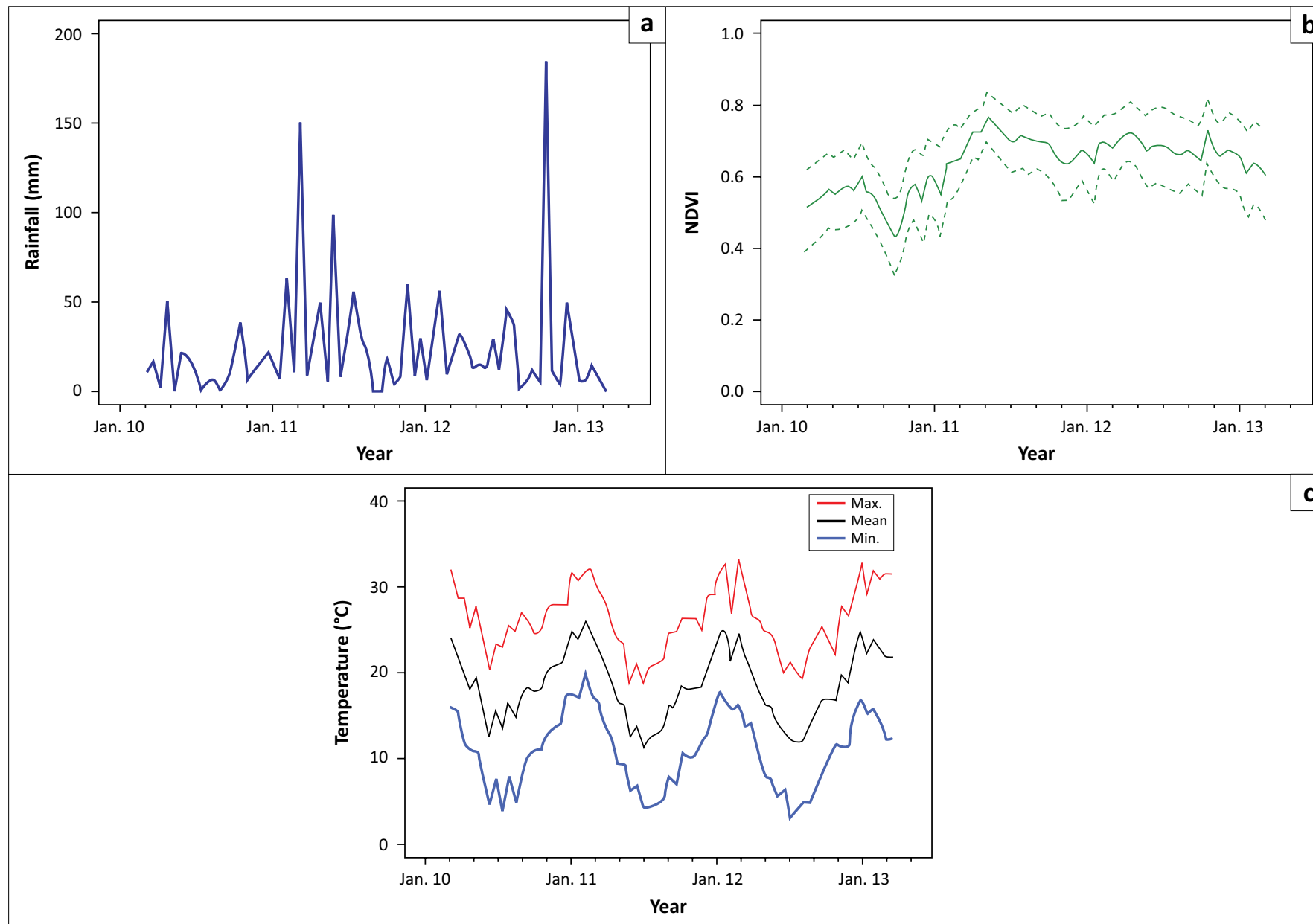

Temperature values reflecting the mean (black), minimum (blue) and maximum (red) daily temperature during the study period were averaged across sixteen-day periods matching the Normalised Difference Vegetation Index Moderate Resolution Imaging Spectroradiometer composites.

FIGURE 1-A1: Addo Elephant National Park features an aseasonal climate. (a) Rainfall (mm) during the study period (06 March 2010 - 21 March 2013 ). Rainfall records are aggregated to 16-day periods matching the Normalised Difference Vegetation Index Moderate Resolution Imaging Spectroradiometer composites. (b) Mean Normalised Difference Vegetation Index (solid line) \pm 1 standard deviation (dashed lines) during the study period. The mean and standard deviation of Normalised Difference Vegetation Index were calculated across the three elephant-accessible sections of Addo Elephant National Park: Main Camp, Colchester and Nyathi. (c) While the rainfall and Normalised Difference Vegetation Index patterns are aseasonal, temperature follows more regular annual patterns.

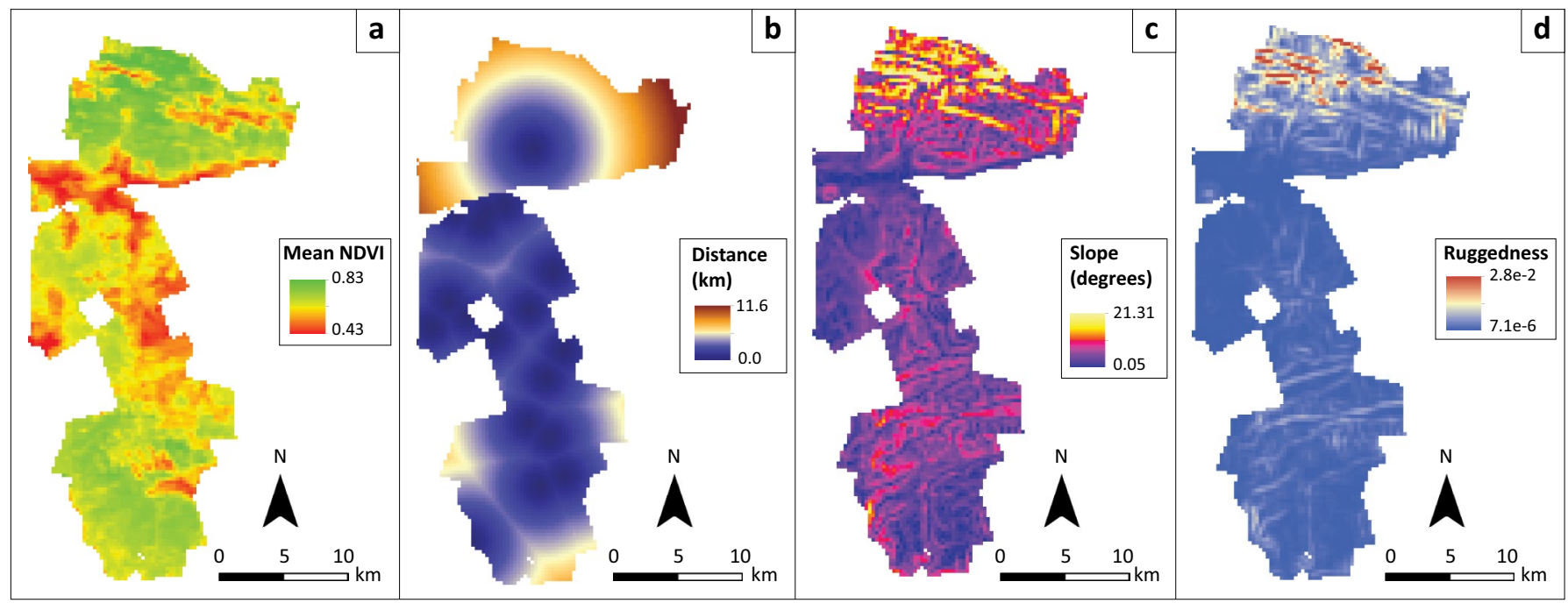

Note that Normalised Difference Vegetation Index in the models was included as time-specific Normalised Difference Vegetation Index values obtained from 70 sixteen-day Moderate Resolution Imaging Spectroradiometer composites (see the main text for details). However, the mean Normalised Difference Vegetation Index across the study period (06 March $2010-21$ March 2013 ) is displayed here for visualisation period to allow comparison of general trends in Normalised Difference Vegetation Index values over space.

FIGURE 2-A1: Covariate data used as inputs into step selection function models for resource selection by female elephants in Addo Elephant National Park, South Africa. Covariates modelled included (a) Normalised Difference Vegetation Index, (b) distance to artificial water, (c) slope and (d) terrain ruggedness. 


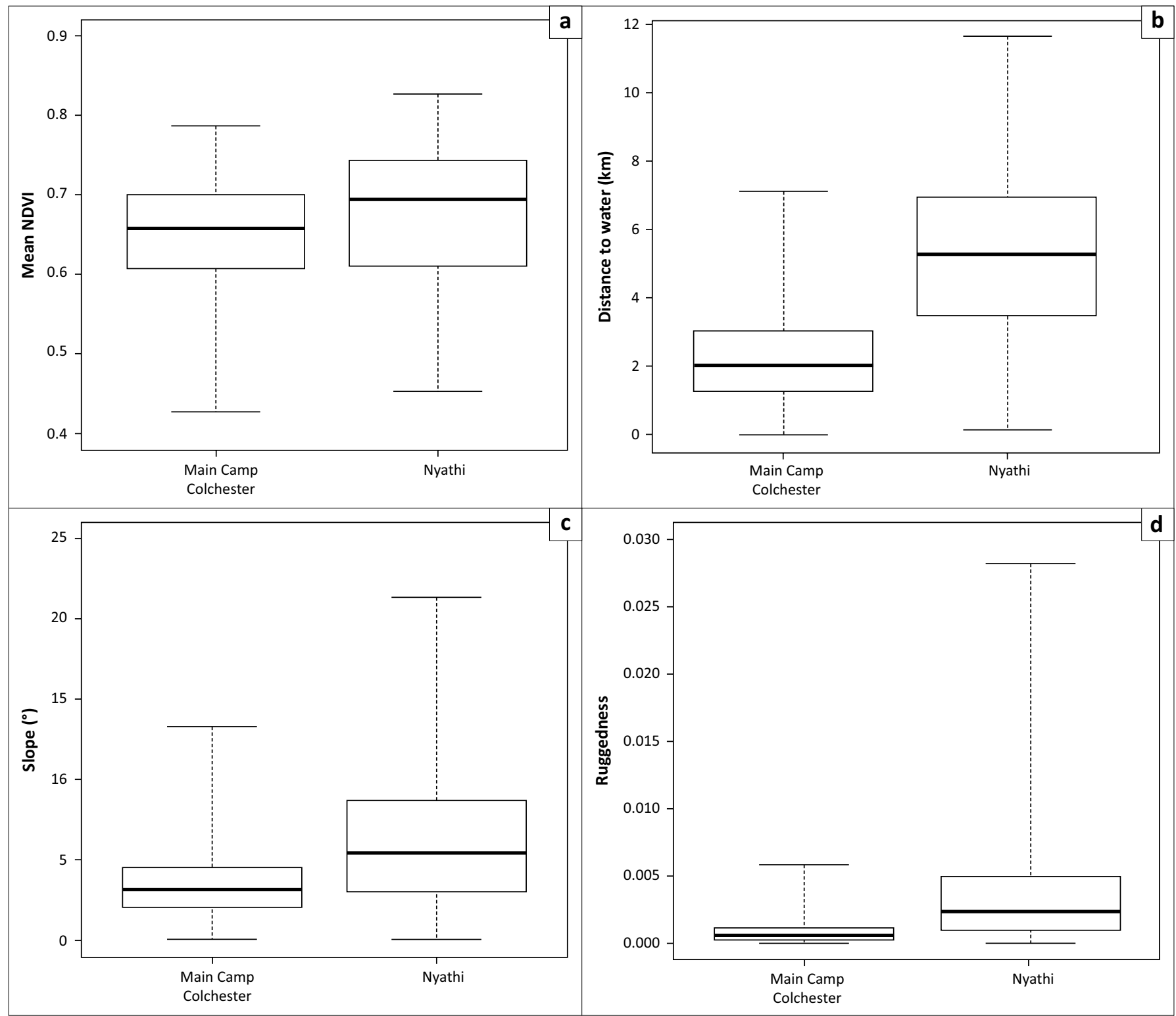

Box plots depict the median value (thick horizontal line), upper and lower quantiles (box boundary) and range (whiskers). The Normalised Difference Vegetation Index box plot and Wilcoxon ranksum test were based on the mean Normalised Difference Vegetation Index values depicted in Figure 2-A1 rather than on the time-specific Normalised Difference Vegetation Index layers used in the step selection function models. Note that the $y$-axes differ between plots.

FIGURE 3-A1: Covariate values differed between the Main Camp - Colchester and Nyathi sections for (a) Normalised Difference Vegetation Index (Wilcoxon rank-sum test $W=3517400, p<0.001)$, (b) distance to artificial water ( $W=1270300, p<0.001)$, (c) slope ( $W=2636900, p<0.001)$ and (d) terrain ruggedness ( $W=1871300$, $p<0.001)$. 


\section{Appendix 2: Elephant location data summary}

TABLE 1-A2: Descriptive statistics of daily elephant location data recorded in the morning (06:00), midday (12:00) and afternoon (16:00). For each parameter, the mean \pm s.d. is reported for seven female elephants in Addo Elephant National Park, South Africa.

\begin{tabular}{|c|c|c|c|}
\hline Data set & Recorded locations & Positional dilution of precision $\dagger$ & Daily step length (m) \\
\hline 06:00 & $728 \pm 193$ & $2.4 \pm 1.3$ & $2151.5 \pm 1753.4$ \\
\hline $12: 00$ & $870 \pm 157$ & $2.0 \pm 1.1$ & $2127.1 \pm 1816.9$ \\
\hline $16: 00$ & $904 \pm 165$ & $2.0 \pm 1.0$ & $2267.5 \pm 1895.0$ \\
\hline
\end{tabular}

$\dagger$, Positional dilution of precision provides a unitless indicator of position accuracy, reflecting how satellite geometry affects the accuracy of a recorded location, with lower Positional dilution of precision values indicating a higher level of accuracy.

TABLE 2-A2: Descriptive statistics of daily elephant location data recorded in the morning (06:00), midday (12:00) and afternoon (16:00). For each parameter, the mean \pm s.d. is reported for the six female elephants occupying the Main Camp - Colchester section of Addo Elephant National Park, South Africa.

\begin{tabular}{|c|c|c|c|}
\hline Data set & Recorded locations & Positional dilution of precision $\dagger$ & Daily step length (m) \\
\hline 06:00 & $712 \pm 206$ & $2.3 \pm 1.3$ & $1989.7 \pm 1623.2$ \\
\hline $12: 00$ & $854 \pm 165$ & $2.0 \pm 1.1$ & $1990.8 \pm 1744.0$ \\
\hline 16:00 & $889 \pm 176$ & $1.9 \pm 1.0$ & $2147.5 \pm 1838.8$ \\
\hline
\end{tabular}

$\dagger$, Positional dilution of precision provides a unitless indicator of position accuracy, reflecting how satellite geometry affects the accuracy of a recorded location, with lower Positional dilution of precision values indicating a higher level of accuracy. 


\section{Appendix 3: Availability sample size sensitivity analysis}

Following the guidance of Northrup et al. (2013), we conducted a sensitivity analysis on the effects of the size of the availability sample on our conditional logistic regression (CLR) coefficient estimates. For each used elephant location, a candidate set of 100 potentially available locations was drawn as described in the main text. We tested seven availability ratios ranging from 1 to 50 available locations per used location (availability ratios $=1,3,5,10,20,35$ and 50). We fit CLR models using the full time-interacted model (Model 30 in Table 1) with available points randomly selected from the candidate set. This was repeated 100 times for each availability ratio, and the mean coefficient estimate and $95 \%$ simulation envelope were calculated. The sensitivity analysis was repeated for each of the three daily elephant data sets (morning [06:00], midday [12:00] and afternoon [16:00]).

Simulation results indicated relatively small changes in regression coefficient estimates across varying availability ratios (Figure 1-A3 Figure 3-A3). Simulation envelopes grew narrower as the availability ratio increased and coefficient estimates tended to stabilise at around 20 available locations per used location. Coefficient estimates for the time-interacted covariates (not shown here) showed similar patterns to the time-independent coefficients. In light of these results, we used an availability ratio of 20 available locations for each used location in subsequent analyses.

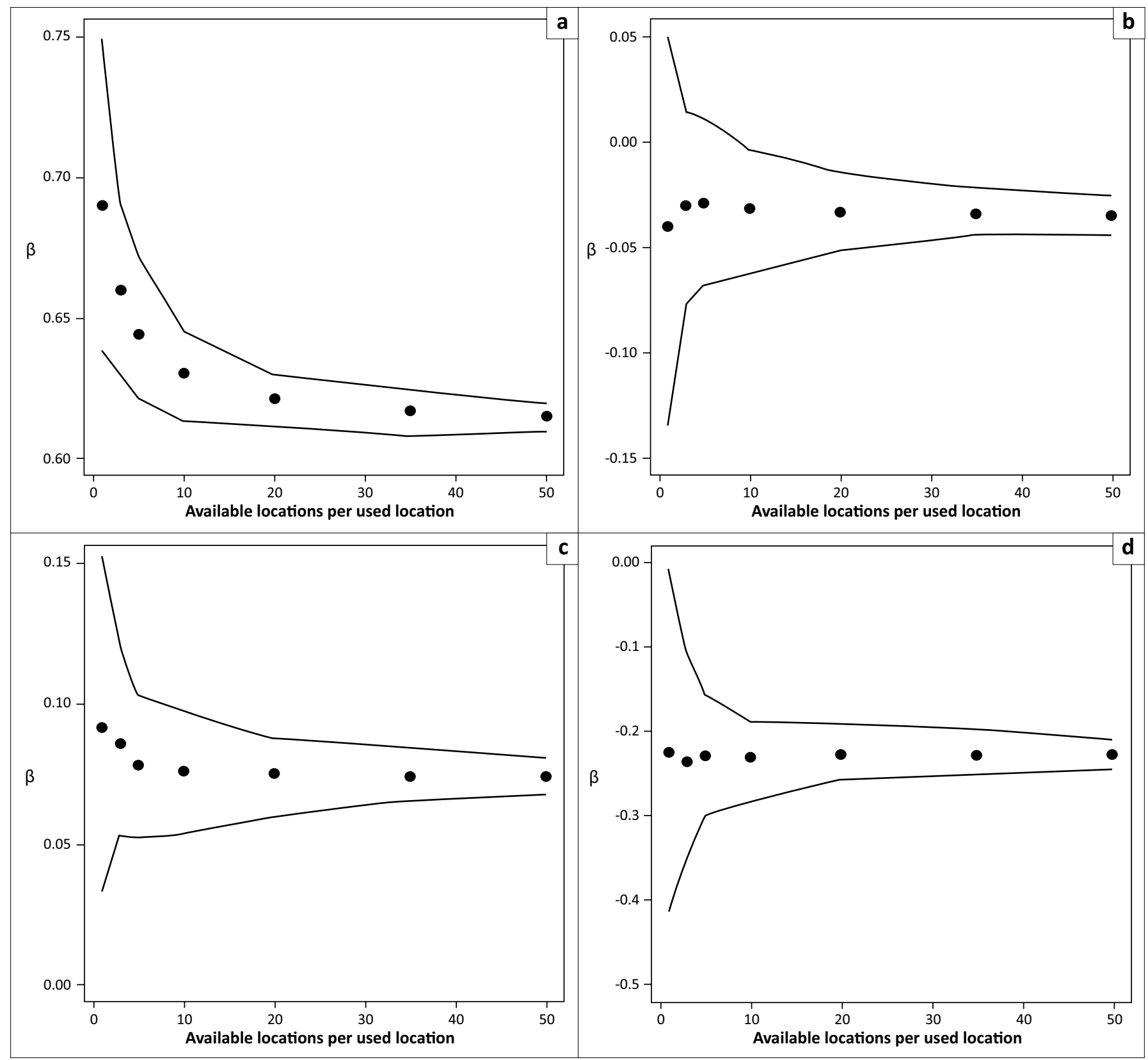

Note that $y$-axes vary across panels.

FIGURE 1-A3: Coefficient estimates (black points) and 95\% simulation envelopes (solid lines) for (a) the Normalised Difference Vegetation Index, (b) distance to water, (c) slope and (d) terrain ruggedness, calculated from 100 conditional logistic regression models fit to varying ratios of available to used elephant locations recorded at 06:00. 

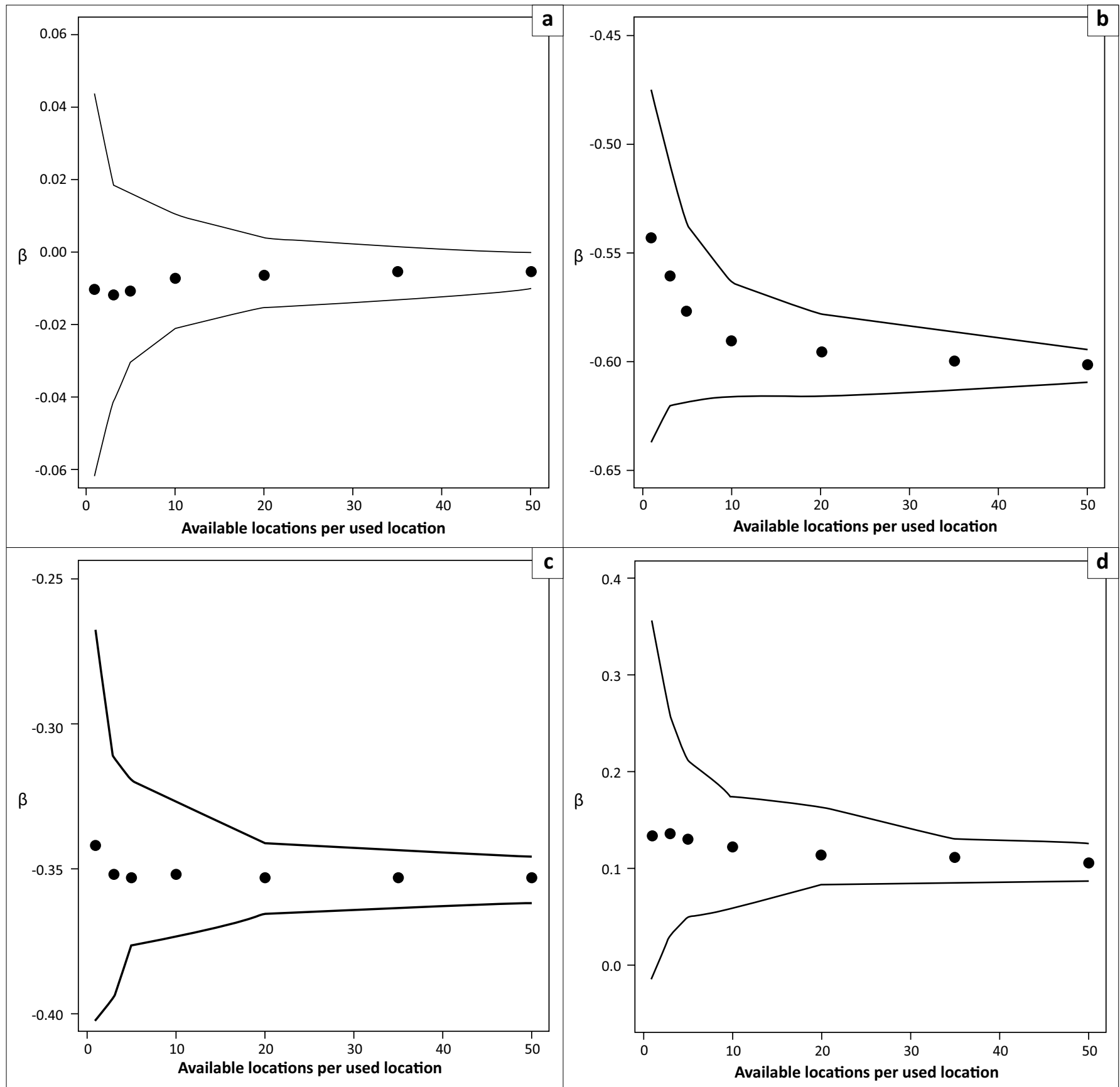

Note that $y$-axes vary across panels.

FIGURE 2-A3: Coefficient estimates (black points) and 95\% simulation envelopes (solid lines) for (a) Normalised Difference Vegetation Index, (b) distance to water,

(c) slope and (d) terrain ruggedness, calculated from 100 conditional logistic regression models fit to varying ratios of available to used elephant locations recorded at 12:00. 


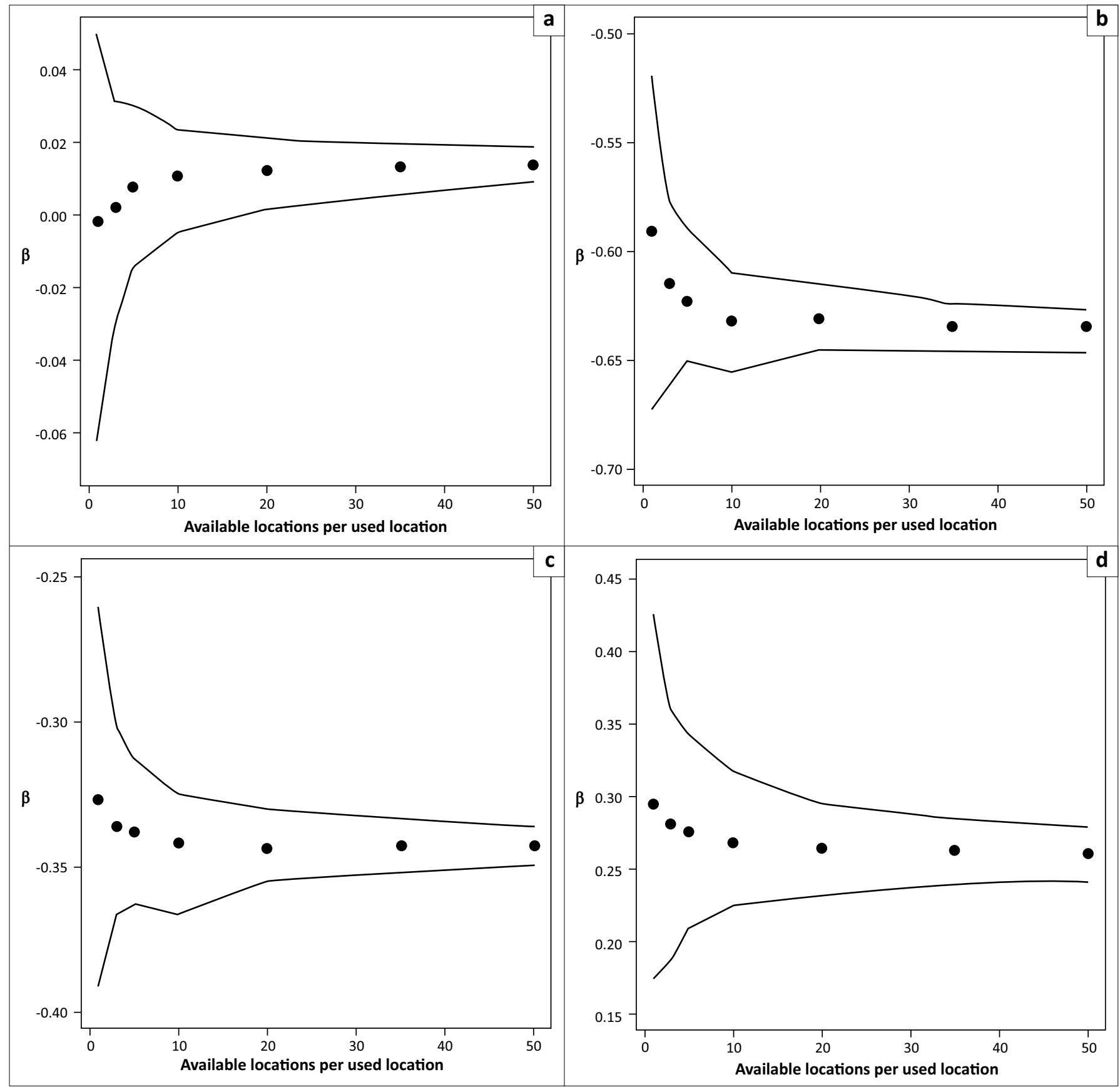

Note that $y$-axes vary across panels.

FIGURE 3-A3: Coefficient estimates (black points) and 95\% simulation envelopes (solid lines) for (a) Normalised Difference Vegetation Index, (b) distance to water, (c) slope and (d) terrain ruggedness, calculated from 100 conditional logistic regression models fit to varying ratios of available to used elephant locations recorded at 16:00. 


\section{Appendix 4: Elephant predicted use animations}

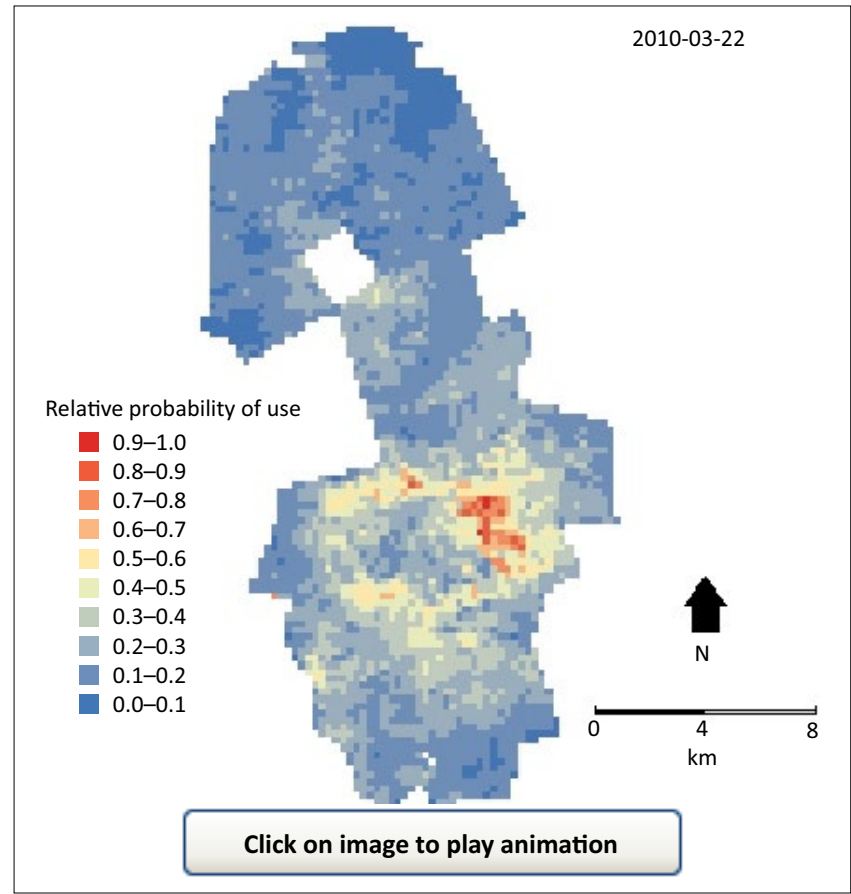

To view the animation online, visit https://youtu.be/fLotTDNC_vc

FIGURE 1-A4: Animation of predicted space use by female elephants in the morning (06:00) in Addo Elephant National Park, South Africa. Predicted use reflects step selection function model predictions to the elephant-accessible Main Camp - Colchester section of Addo Elephant National Park for 16-day periods from 06 March 2010 to 21 March 2013, corresponding to the Moderate Resolution Imaging Spectroradiometer composites used for analysis (see the main text for details)

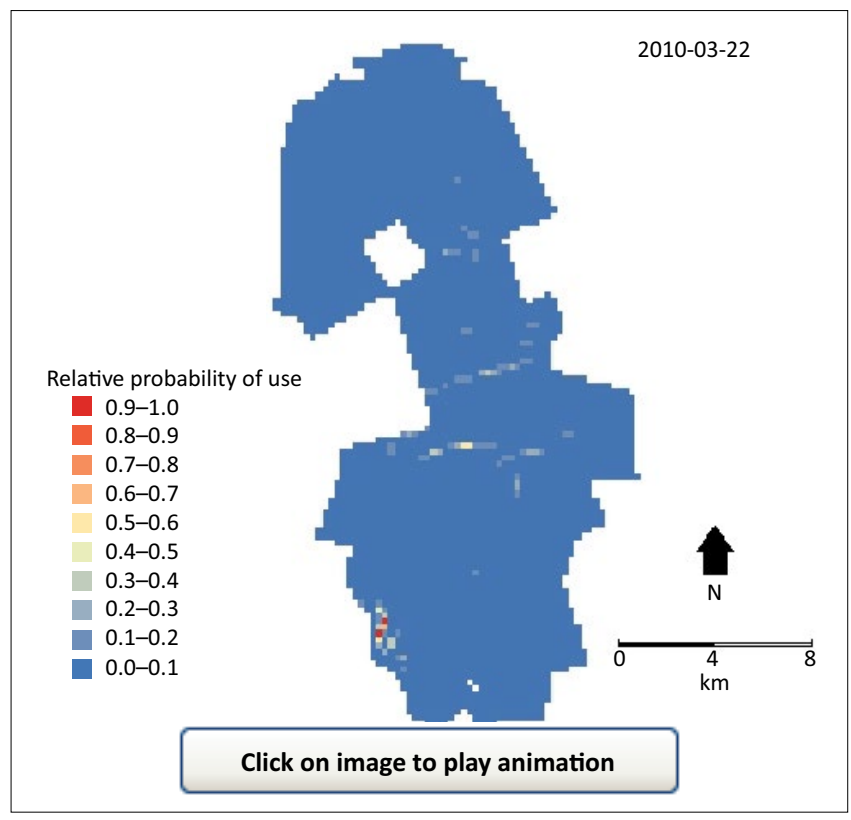

To view the animation online, visit https://youtu.be/fAlq91r7xQ8

FIGURE 2-A4: Animation of predicted space use by female elephants at midday (12:00) in Addo Elephant National Park, South Africa. Predicted use reflects step selection function model predictions to the elephant-accessible Main Camp Colchester section of Addo Elephant National Park for 16-day periods from 06 March 2010 to 21 March 2013, corresponding to the Moderate Resolution Imaging Spectroradiometer composites used for analysis (see the main text for details).

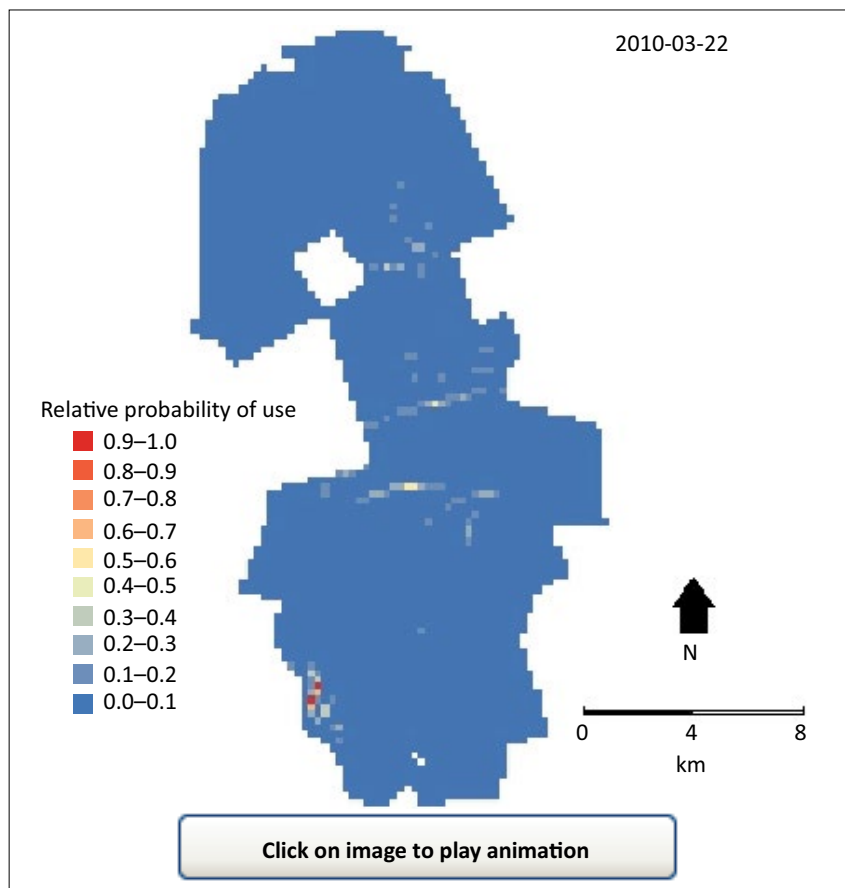

To view the animation online, visit https://youtu.be/RtBWDBQioGU

FIGURE 3-A4: Animation of predicted space use by female elephants in the afternoon (16:00) in Addo Elephant National Park, South Africa. Predicted use reflects step selection function model predictions to the elephant-accessible Main Camp - Colchester section of Addo Elephant National Park for 16-day periods from 06 March 2010 to 21 March 2013, corresponding to the Moderate Resolution Imaging Spectroradiometer composites used for analysis (see the main text for details).

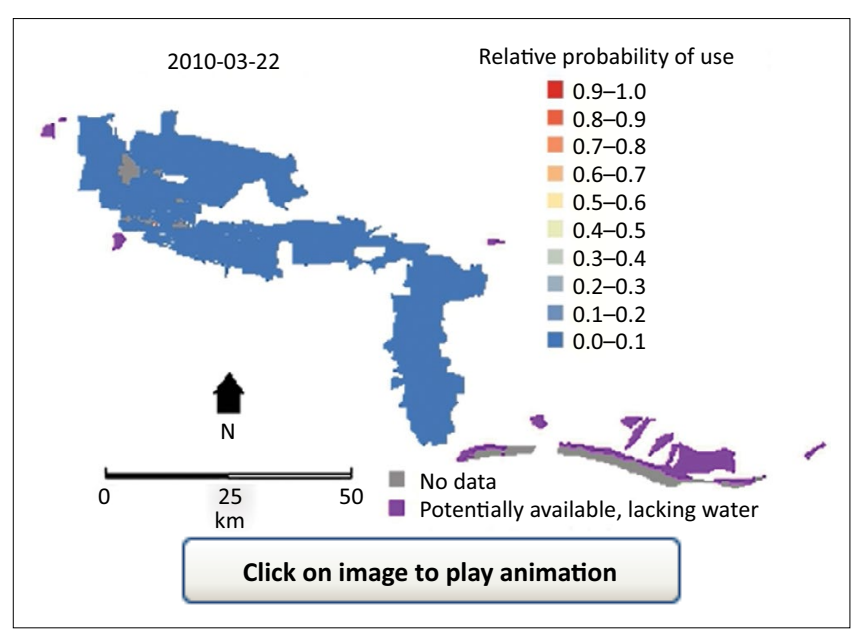

Areas of 'no data' represent locations dominated by water, such as Darlington Dam in the north and the coastline of the Indian Ocean in the south, as well as areas with Moderate Resolution Imaging Spectroradiometer pixel reliability values greater than 1. Areas in purple fall within Addo Elephant National Park but currently lack permanently available fresh water, making them unsuitable for elephant use.

To view the animation online, visit https://youtu.be/RzptVzB_7CM

FIGURE 4-A4: Animation of predicted space use by female elephants across Addo Elephant National Park, South Africa. Predicted use reflects midday (12:00) step selection function model extrapolations to the full Addo Elephant National Park, including areas that are currently not accessible to elephants. Predictions represent 16-day periods from 06 March 2010 to 21 March 2013, corresponding to the Moderate Resolution Imaging Spectroradiometer composites used for analysis (see the main text for details). 